\title{
GLIPR1L1 is an IZUMO-binding protein required for optimal fertilization in the mouse
}

\author{
Avinash S. Gaikwad', Amanda L. Anderson², D. Jo Merriner', Anne E. O'Connor', Brendan J. Houston', \\ R. John Aitken ${ }^{2}$, Moira K. O'Bryan ${ }^{1 * \dagger}$ and Brett Nixon ${ }^{2 *+}$ (D)
}

\begin{abstract}
Background: The sperm protein IZUMO1 (Izumo sperm-egg fusion 1) and its recently identified binding partner on the oolemma, IZUMO1R, are among the first ligand-receptor pairs shown to be essential for gamete recognition and adhesion. However, the IZUMO1-IZUMO1R interaction does not appear to be directly responsible for promoting the fusion of the gamete membranes, suggesting that this critical phase of the fertilization cascade requires the concerted action of alternative fusogenic machinery. It has therefore been proposed that IZUMO1 may play a secondary role in the organization and/or stabilization of higher-order heteromeric complexes in spermatozoa that are required for membrane fusion.

Results: Here, we show that fertilization-competent (acrosome reacted) mouse spermatozoa harbor several high molecular weight protein complexes, a subset of which are readily able to adhere to solubilized oolemmal proteins. At least two of these complexes contain IZUMO1 in partnership with GLI pathogenesis-related 1 like 1 (GLIPR1L1). This interaction is associated with lipid rafts and is dynamically remodeled upon the induction of acrosomal exocytosis in preparation for sperm adhesion to the oolemma. Accordingly, the selective ablation of GLIPR1L1 leads to compromised sperm function characterized by a reduced ability to undergo the acrosome reaction and a failure of IZUMO1 redistribution.
\end{abstract}

Conclusions: Collectively, this study characterizes multimeric protein complexes on the sperm surface and identifies GLIPRL1L1 as a physiologically relevant regulator of IZUMO1 function and the fertilization process.

Keywords: Spermatozoa, Fertilization, Capacitation, IZUMO, GLIPR1L1, Oolemma, Male fertility, Male infertility

\section{Background}

Mammalian fertilization is underpinned by a number of sequential interactions between sperm and oocytes that culminate in a complex process of membrane adhesion and fusion [1]. The understanding of the molecular basis of gamete interactions has been advanced by an elegant series of transgenic and biochemical studies focusing on the sperm protein IZUMO1, and its oolemmal binding partner, IZUMO1R (sperm-egg fusion protein Juno) [2]. IZUMO1 is a type 1 transmembrane protein [3] that localizes to both

\footnotetext{
* Correspondence: moira.obryan@monash.edu; Brett.Nixon@newcastle.edu.au ${ }^{+}$Moira K. O'Bryan and Brett Nixon contributed equally to this work.

'The School of Biological Sciences, Monash University, Melbourne, VIC 3800 Australia

${ }^{2}$ Priority Research Centre for Reproductive Science, School of Environmental and Life Sciences, University of Newcastle, Callaghan, NSW 2308, Australia
}

the inner and outer acrosomal membranes of spermatozoa before undergoing dynamic relocalization to the cell surface upon completion of an acrosome reaction [4]. From this latter position, IZUMO1 directs gamete recognition and adhesion via multiple low-affinity interactions with IZUMO1R, a GPI-linked receptor that resides on the surface of the oolemma [5]. The indispensable nature of this interaction has been confirmed through complementary in vitro antibody inhibition and in vivo knockout studies targeting Izumo1 and Izumo1r, all of which effectively block the fertilization cascade at the level of gamete adhesion/fusion [2]. Bianchi and colleagues [6] have, however, shown that the IZUMO1-IZUMO1R interaction does not directly promote membrane fusion. Indeed, while the ectopic expression of IZUMO1R in HEK293 cells

(c) The Author(s). 2019 Open Access This article is distributed under the terms of the Creative Commons Attribution 4.0 International License (http://creativecommons.org/licenses/by/4.0/), which permits unrestricted use, distribution, and reproduction in any medium, provided you give appropriate credit to the original author(s) and the source, provide a link to the Creative Commons license, and indicate if changes were made. The Creative Commons Public Domain Dedication waiver (http://creativecommons.org/publicdomain/zero/1.0/) applies to the data made available in this article, unless otherwise stated. 
is successful in promoting their adhesion, it fails to induce the formation of syncytia among these cells [6, 7]. Similarly, cultured cells expressing mouse IZUMO1 can bind to oocytes, but fail to fuse with them [8-10]. Such findings are seemingly at odds with the demonstration that sperm from Izumo1 null males are capable of binding to but not fusing with the oolemma [3].

These apparently contradictory results may be reconciled by the existence of alternative IZUMO1 receptor(s) that mediate gamete membrane fusion [7] or by the propensity of IZUMO1 to associate with other, as yet unidentified sperm surface proteins, leading to the formation of several higher-order multiprotein complexes [11]. Thus, in addition to its direct binding to IZUMO1R, it has been suggested that IZUMO1 may play a secondary role in gamete fusion by virtue of its ability to organize and/or stabilize fusogenic proteins within the sperm membrane [12]. Alternatively, and as explored herein, IZUMO1 may be associated with other key regulators of sperm receptor organization and fusion. Such models of gamete fusion share analogy with the mechanisms that underpin membrane fusion in many other biological systems where the concerted action of multiprotein complexes is a wellestablished paradigm. For instance, it is widely accepted that a majority of enveloped viruses use protein complexes to regulate their progression through the sequential phases of fusion with a suitable target cell membrane, i.e., receptor recognition, triggering of fusion, and fusion execution $[13,14]$. The complexity of this membrane fusion machinery ranges from the use of multiple copies of a single glycoprotein for the entire fusion reaction [15], through to the segregation of the activities responsible for membrane attachment and membrane fusion into different proteins and separate multimeric complexes [16].

Analysis of the protein domains that are required for IZUMO1 complex formation has identified two distinct regions, each putatively involved in the formation of unique complexes [11]. It is proposed that the N-terminal IZUMO domain participates in formation of smaller complexes, whereas the transmembrane domain and/or the cytoplasmic tail direct the formation of larger complexes. The existence of unique pools of IZUMO1 complexes is further supported by the demonstration that different IZUMO1 antibodies localize the protein either exclusively within the equatorial segment [17] or, alternatively, on the entire/anterior acrosomal region of acrosome-reacted sperm $[3,11]$. While the identity of the putative IZUMO1-interacting proteins has yet to be established, the use of genomic and proteomic techniques has uncovered several candidate molecules with putative roles in sperm-oocyte interaction [18], including various members of the ADAM (a disintegrin and metalloprotease domain) [19] and CAP (cysteinerich secretory proteins, antigen 5 , and pathogenesis-related 1 proteins) superfamily of enzymes [20].
The aim of the current study was to investigate whether mouse spermatozoa harbor multimeric complexes that participate in oolemma interactions and, if so, identify some of the key proteins in these complexes. Using the combined techniques of blue native PAGE and far-western blotting, we successfully demonstrated that mouse spermatozoa do possess multimeric protein complexes that readily bind solubilized oolemmal proteins. A subset of these complexes contain IZUMO1 and the CAP proteins GLI pathogenesis-related 1 like 1 (GLIPR1L1). Indeed, the analysis of a knockout mouse model revealed that GLIPR1L1 is required for optimal fertilization, with the loss of this protein leading to the dysregulation of acrosomal exocytosis, a failure of IZUMO1 relocalization and poor in vitro fertilization rates.

\section{Results}

\section{Identification of oolemmal binding complexes in mouse spermatozoa}

Mouse spermatozoa harbor at least four putative solubilized oolemmal protein-binding complexes that range in molecular weight from 260 to $750 \mathrm{kDa}$ (complexes I-IV; Fig. 1a). Of note, a similar profile of labeled complexes was observed irrespective of whether lysates were prepared from non-capacitated, capacitated, or capacitated sperm that were treated with the calcium ionophore, A23187, under conditions that robustly stimulate acrosomal exocytosis in approximately $70 \%$ of the cells. However, lysates from the latter two samples appeared to bind more oolemmal proteins than that of noncapacitated spermatozoa.

Mass spectrometry analysis of the predominant oolemma protein binding band at $\sim 750 \mathrm{kDa}$ (complex I) identified several peptides corresponding to IZUMO1 and GLIPR1L1 (Table 1). To validate these findings, IZUMO1 and GLIPR1L1 antibodies were used to probe extracts of mouse spermatozoa under reducing and native conditions. Consistent with our previous work [21], under reducing conditions, the GLIPR1L1 antibody bound to a predominant band with a molecular weight of $37 \mathrm{kDa}$, while the IZUMO1 antibody bound to a protein with a mass of $\sim 56 \mathrm{kDa}$ (Fig. 1b). Further, immunoblot analysis of native sperm lysates with these antibodies revealed strong binding with several very high molecular weight protein bands, raising the possibility that both IZUMO1 and GLIPR1L1 associate with additional sperm proteins to form multimeric complexes (Fig. 1c). Specifically, probing with IZUMO1 antibodies labeled at least six protein bands of $\sim 150-750 \mathrm{kDa}$, supporting previous work that IZUMO1 associates with other proteins to form multimeric complexes on the surface of mouse spermatozoa [11]. GLIPR1L1 was detected in association with six predominant complexes of $\sim 200-1000 \mathrm{kDa}$. The number of complexes recognized by both antibodies did not 


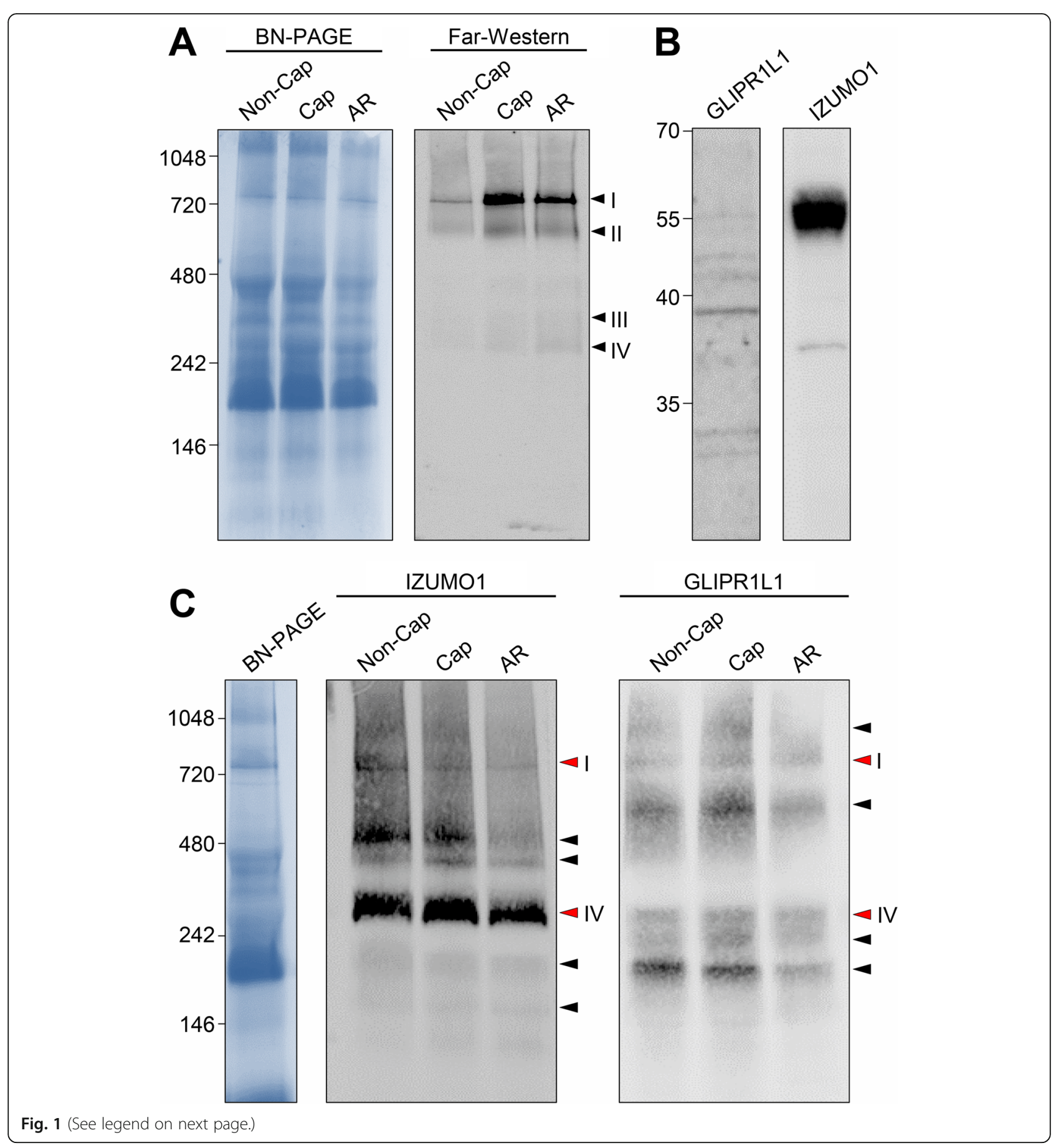


(See figure on previous page.)

Fig. 1 Identification of mouse sperm multimeric protein complexes with affinity for homologous oolemmal proteins. a Mouse spermatozoa were purified under non-capacitating (Non-Cap) or capacitating (Cap) conditions. A portion of the latter population was also challenged with A23187 to induce the acrosome reaction (AR). To detect native protein complexes with affinity for oolemmal proteins, far-western blotting with biotinlabeled preparations of oocyte lysates (Far-Western) was undertaken. Four predominant oolemmal protein-binding complexes (arrowheads, I-IV) were identified. Each experiment was replicated a minimum of three times and representative gels and blots are shown. The numbers on the left correspond to the molecular weight $(\mathrm{kDa})$ of native PAGE protein standards. $\mathbf{b}$ Validation of GLIPR1L1 and IZUMO1 antibodies. The specificity of the antibodies used in this study was confirmed by immunoblotting against sperm protein extracts. This experiment was replicated three times and immunoblots are shown. The numbers on the left correspond to the molecular weight of the protein standards. c Identification of mouse sperm protein complexes comprising IZUMO1 and GLIPR1L1. Populations of non-capacitated (Non-Cap), capacitated (Cap), and acrosome-reacted (AR) mouse spermatozoa were solubilized in blue native lysis buffer. The extracted proteins were resolved on BN-PAGE gels before being prepared for immunoblotting with either IZUMO1 or GLIPR1L1 antibodies. Arrowheads indicate the predominant complexes recognized by each antibody. Red arrowheads correspond to complexes (I and IV) that co-migrated with those that bound oolemmal proteins (see Fig. 1a). Each experiment was replicated a minimum of three times and representative images are shown. The numbers on the left correspond to the molecular weight $(\mathrm{kDa})$ of native PAGE protein standards

appear to change between non-capacitated, capacitated, or capacitated and A23187-treated sperm, although quantitative changes were observed wherein there appeared to be some loss of each complex in the latter sample. Importantly, both IZUMO1 and GLIPR1L1 were localized with a band consistent with oolemmal protein-binding complex I $(\sim 750 \mathrm{kDa})$. They also colocalized to complex IV (Fig. 1a, c, complexes I and IV, marked in red arrowheads). Given that the combined molecular weight of IZUMO1 and GLIPR1L1 is, however, below that of complexes I and IV, it is likely that they contain additional components that were not identified in our mass spectrometry (MS) analysis.

\section{IZUMO1 and GLIPR1L1 form stable complex(es) in mouse spermatozoa}

In order to assess if the protein bands recognized by IZUMO1 and GLIPR1L1 antibodies were multimeric entities, 2D blue native-polyacrylamide gel electrophoresis (BN-PAGE) was performed to separate individual constituents within the complexes (Fig. 2a, b). Immunoblotting of 2D BN-PAGE membranes confirmed the presence of IZUMO1 and GLIPR1L1 in complexes I and IV (Fig. 2c). Interestingly, unique isoforms of GLIPR1L1 resolved within each of the complexes, such that the 47-kDa GLIPR1L1 isoform was detected in complex I and the 37- and 32kDa GLIPR1L1 isoforms were predominantly detected in complex IV.

In view of the novelty of our findings, a number of strategies were employed to further examine the interaction between IZUMO1 and GLIPR1L1 in oolemmal adhesion complex(es). Firstly, co-immunoprecipitation using the IZUMO1 antibody from lysates of acrosomereacted spermatozoa pulled down GLIPR1L1, and a reciprocal co-immunoprecipitation with the GLIPR1L1 antibody successfully isolated IZUMO1 (Fig. 3).

An investigation of the ontogeny of protein expression also revealed overlapping patterns of labeling in developing male germ cells and mature spermatozoa. Both proteins displayed a similar diffuse labeling of pachytene spermatocytes and round spermatids (Fig. 4a, b) but were clearly represented in the head of mature spermatozoa where they were primarily localized to the periacrosomal region. Consistent with our previous findings [21], additional GLIPR1L1 labeling was detected in a discrete spot at the posterior aspect of the sperm head corresponding to the connecting piece (Fig. 4c). Following the induction of the acrosome reaction, detected by

Table 1 Mass spectrometry identification of proteins resolving in complex I

\begin{tabular}{|c|c|c|c|c|c|c|c|}
\hline Accession & Description & \# Unique peptides & Coverage (\%) & \# Amino acids & Molecular weight (kDa) & pl & Mascot Score \\
\hline \multirow[t]{6}{*}{ Q9D9J7 } & \multirow{6}{*}{$\begin{array}{l}\text { Izumo sperm-egg fusion } \\
\text { protein } 1 \text { (IZUMO1) }\end{array}$} & 5 & \multirow[t]{6}{*}{13.9} & \multirow[t]{6}{*}{397} & \multirow[t]{6}{*}{44.9} & \multirow[t]{6}{*}{6.3} & \multirow[t]{6}{*}{106} \\
\hline & & DIFNNLAR & & & & & \\
\hline & & SMVGPEDAGNYR & & & & & \\
\hline & & SEDLVLDCLLSWHR & & & & & \\
\hline & & YDVTVLPPK & & & & & \\
\hline & & SDQSLSQQMGLK & & & & & \\
\hline \multirow[t]{4}{*}{ Q9DAG6 } & \multirow{4}{*}{$\begin{array}{l}\text { GLI pathogenesis-related } \\
\text { 1-like } 1 \text { (GLIPR1L1) }\end{array}$} & 3 & \multirow[t]{4}{*}{14.0} & \multirow[t]{4}{*}{236} & \multirow[t]{4}{*}{27.1} & \multirow[t]{4}{*}{8.6} & \multirow[t]{4}{*}{52} \\
\hline & & FIDAFLNIHNELR & & & & & \\
\hline & & LAHNPCIK & & & & & \\
\hline & & IGCAVSNCPNLK & & & & & \\
\hline
\end{tabular}




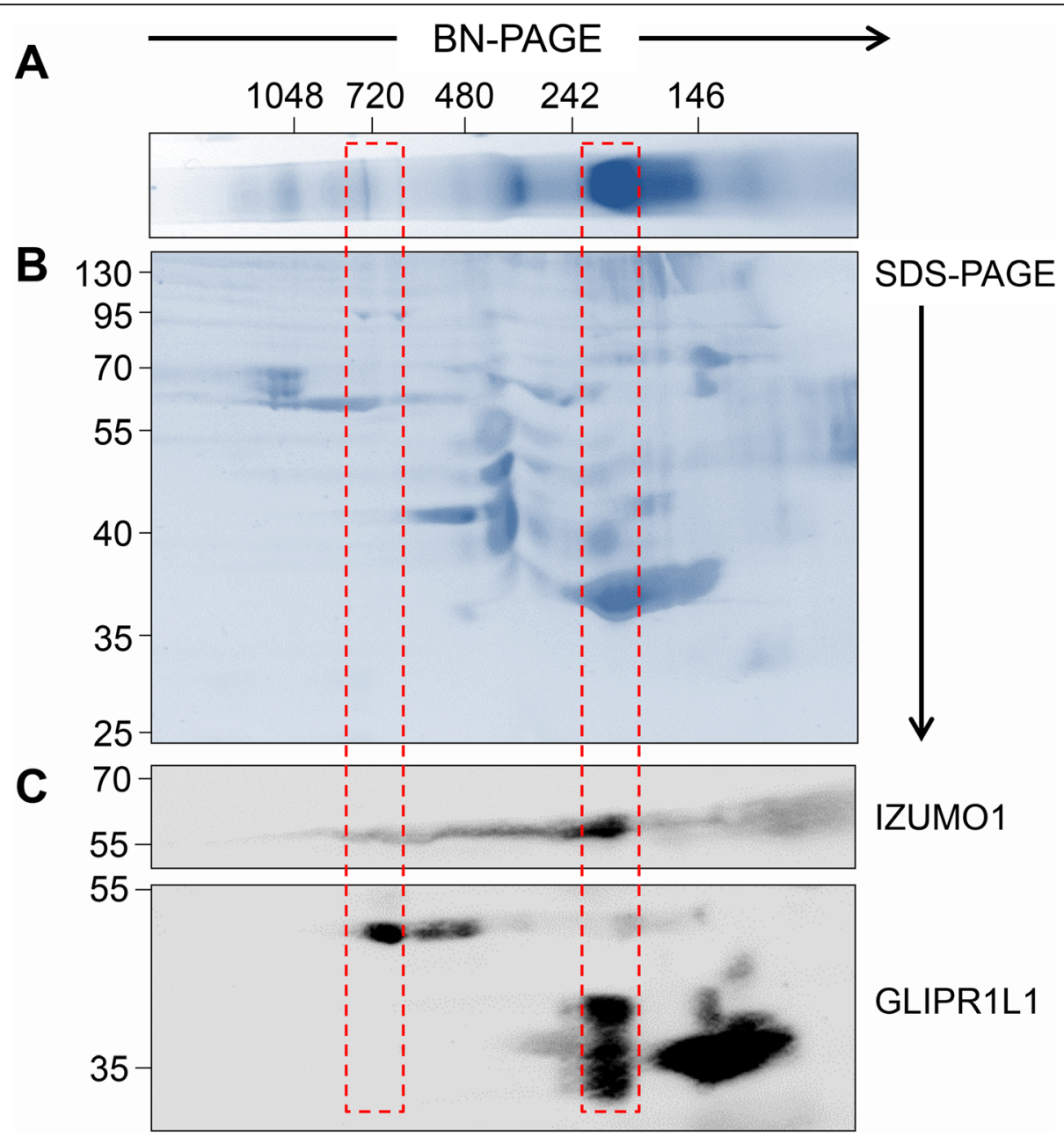

Fig. 2 IZUMO1 and GLIPR1L1 reside in multimeric protein complexes. a Native protein complexes were extracted from acrosome-reacted mouse spermatozoa and resolved by BN-PAGE. b A single lane of the BN-PAGE gel was then placed atop an SDS-PAGE gel and the individual proteins within each complex resolved according to their molecular weight. c Gels were then used for immunoblotting with IZUMO1 or GLIPR1L1 antibodies. Each of these experiments was repeated three times and representative images are shown. The boxed section indicates the position of labeled proteins vertically aligned with complexes I and IV

loss of PNA labeling of the acrosomal domain, both IZUMO1 and GLIPR1L1 were detected throughout the sperm head (Fig. 4d), although the overall intensity of GLIPR1L1 labeling was diminished within acrosomereacted spermatozoa.

In order to assess the topology of interactions, a proximity ligation assay (PLA) was performed. Despite similar immunocytochemical labeling patterns, the use of PLA revealed that IZUMO1 and GLIPR1L1 complexes were not universally distributed through the cytoplasm of developing pachytene spermatocytes and round spermatids (Fig. 5a). Rather, a relatively large number of discrete foci of colocalization were observed, few of which were present in the developing acrosomal domain. Unexpectedly, PLA staining for the complex was virtually absent in epididymal spermatozoa before re-emerging within the head of $>90 \%$ of acrosome-reacted spermatozoa (Fig. 5b, c). Importantly, a suite of controls utilizing antibodies against proteins that should not interact with IZUMO1, such as acrosin and $\alpha$ tubulin, as well as single antibody only controls, failed to demonstrate the presence of any fluorescent signals (Additional file 1: Figure S1) indicating that the interaction observed between IZUMO1 and GLIPR1L1 was specific. Collectively, these results confirm that IZUMO1 and GLIPR1L1 form a protein complex within male germ cells, but that this assemblage is influenced by the maturation status of the cell.

The observed changes in protein localization prompted us to investigate whether the interaction between IZUMO1 and GLIPR1L1 is influenced by their partitioning into lipid rafts; microdomains that undergo dynamic repositioning during sperm maturation [22]. The rationale for this experiment is strengthened by previous independent evidence that IZUMO1 and GLIPR1L1 are components of 


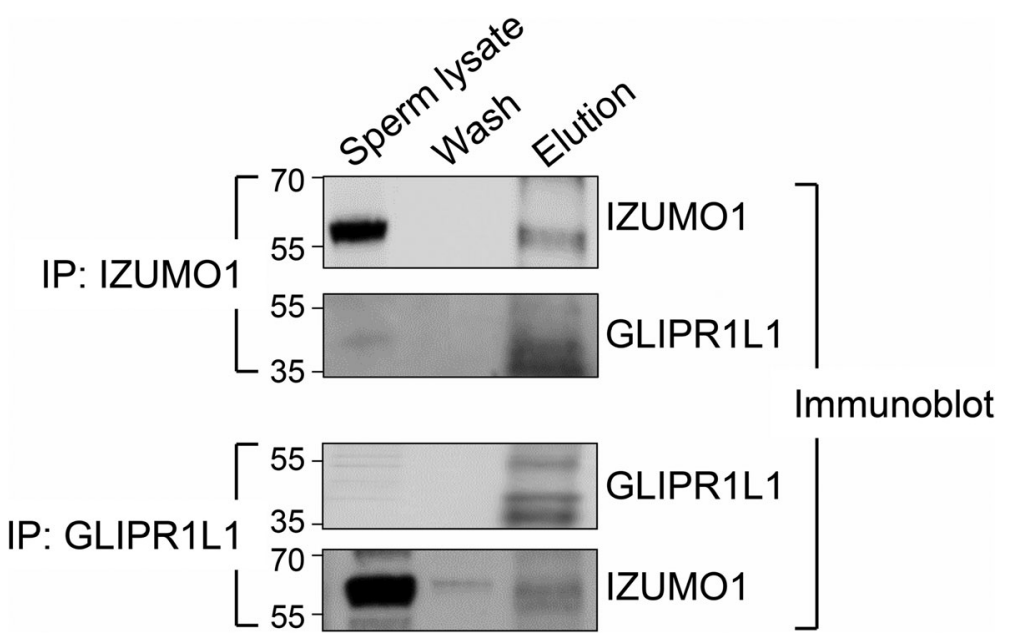

Fig. 3 Interaction between IZUMO1 and GLIPR1L1 using reciprocal co-immunoprecipitation (IP). Acrosome-reacted mouse spermatozoa were subjected to immunoprecipitation using IZUMO1 or GLIPR1L1 antibodies as described in the "Methods" section. Membranes were probed with the target antibody, to confirm the efficacy of immunoprecipitation, before being stripped and re-probed with the alterative antibody to confirm the target protein interaction. Whole sperm lysate was included to confirm the identity of the co-precipitated proteins, as was the material recovered after washing the beads to confirm the specificity of the elution. This experiment was replicated three times and representative blots are depicted

mouse [23] and bovine [24] sperm lipid rafts, respectively. Consistent with the hypothesis, both proteins displayed strong colocalization with $G_{M 1}$ gangliosides in the periacrosomal region of the head of capacitated spermatozoa (Fig. 6). Consistent with previous data, upon the induction of acrosomal exocytosis, $G_{M 1}$ became more widely distributed throughout the anterior region of the sperm head (Fig. 6). Both IZUMO1 and GLIPR1L1 were characterized by a pattern of labeling that closely mirrored that of $\mathrm{G}_{\mathrm{M} 1}$ in the acrosome-reacted cells, thus supporting the hypothesis that IZUMO1 and GLIPR1L1 are found within lipid rafts in mouse sperm.

\section{GLIPR1L1 is required for optimal fertilization}

To assess the role of GLIPR1L1 in IZUMO1 function and male fertility broadly, a Glipr $1 l 1^{-/-}$mouse line was produced. This mouse line contains a 7-bp deletion which was predicted to result in a premature stop codon in exon 1, resulting in a frame-shift mutation and ultimately a 4-kDa fragment of GLIPR1L1 protein (Additional file 2: Figure S2A-B). The mutation resulted in a $92 \%$ reduction in Glipr1l1 testis mRNA expression compared to its corresponding wild type (WT) littermates (Fig. 7a), and an absence of GLIPR1L1 protein, as determined by immunofluorescent labeling (Fig. 7b), thus confirming the successful production of a Glipr1l1 null mouse line.

In order to define the absolute effect of Glipr1l1 deletion on male fertility, mice were examined at a histological and functional level in comparison to WT litter mates. Testicular histology was comparable between WT and Glipr1l1 ${ }^{-/}$ mice (Fig. 8a). Similarly, no significant differences were seen in the number of pups per litter, body weight, testis weight, or daily sperm production between genotypes (Additional file 3: Figure S3A-C, Fig. 8b). Sperm motility was assessed using a computer-assisted sperm analyzer, revealing no significant differences in total or progressive motility and other sperm velocity parameters between genotypes (Fig. 8c-e). Similarly, sperm appeared to capacitate normally as assessed by the time-dependent increase in tyrosine phosphorylation in capacitation permissive media (Fig. 8f, Additional file 4: Figure S4). By contrast, sperm

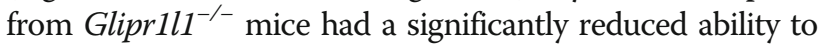
undergo the progesterone-induced acrosome reaction compared to wild type (54\% in WT, $17 \%$ in knockout sperm, $P<0.0001$ ) (Fig. 8g). Collectively, these data illustrate that although GLIPR1L1 is not absolutely required for male fertility, it is required for optimal acrosomal function in vitro and, thus, of likely physiological relevance during the processes of fertilization.

To test the role of GLIPR1L1 in fertilization more precisely, we assessed the ability of WT and Glipr1l1 $1^{-1}$ sperm to bind to the zona pellucida of the oocyte and fertilize in vitro. As shown in Fig. 9, the loss of Glipr1l1 did not affect the ability of sperm to bind to the zona pellucida, but did significantly reduced their ability to fertilize oocytes, as reflected in two-cell embryos, compared to wild type litter mates $(P<0.0200)$. These findings confirm that GLIPR1L1 is required for optimal fertilization at the stage of sperm-oocyte fusion.

\section{GLIPR1L1 is required for redistribution of IZUMO1 in acrosome-reacted spermatozoa}

To investigate the mechanism underpinning this deficit, we tested the effect of Glipr1l1 deletion on IZUMO1 


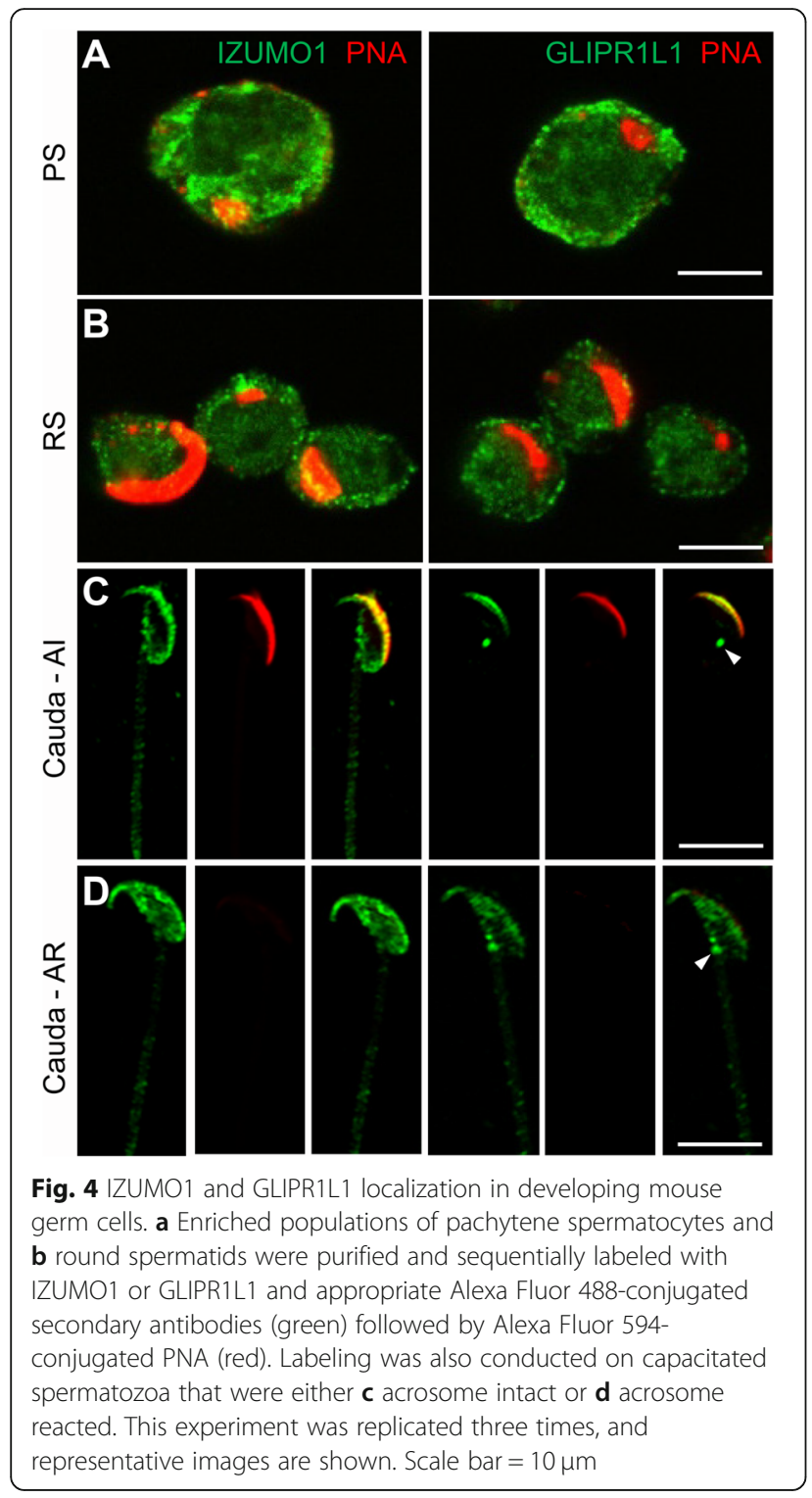

localization. No significant difference was observed between IZUMO1 localization in acrosome intact WT and Gliprll1 $^{-/-}$sperm (Fig. 10a). The relocation of IZUMO1 following the acrosome reaction was, however, qualitatively and quantitatively severely attenuated in Glipr $111^{-/-}$sperm (Fig. 10b). Specifically, in WT sperm following the acrosome reaction, IZUMO1 was relocated throughout the sperm head in $85 \%$ of sperm, compared to $21 \%$ of acrosome-reacted Glipr $1 l 1^{-/-}$sperm $(P<0.0001)$. Collectively, these data reveal that GLIPR1L1 has a role in optimizing acrosome function, the translocation of IZUMO1 during the acrosome reaction, and the fertilization process.

\section{Discussion}

In previous studies, we have isolated biologically active, native protein complexes from mouse and human spermatozoa and demonstrated that several of these multimeric entities possess affinity for homologous zona pellucidae $[25,26]$. Herein, we have extended the analysis to focus on complexes that are present in acrosome-reacted mouse spermatozoa, which may participate in downstream interactions with the oolemma. These studies revealed that sperm do indeed possess multimeric protein complexes with the potential to adhere to solubilized oolemmal proteins. Furthermore, in agreement with independent data [11], we were able to identify the sperm adhesion molecule, IZUMO1, as a key constituent of some, but not all, of these complexes. IZUMO1 has been the subject of intense interest since it was identified as being essential for fertilization [2, 3, 27, 28]. Interestingly, the protein lacks a fusogenic domain and properties commensurate with those expected of a membrane fusion-inducing molecule. Additionally, while the ectopic expression of IZUMO1, or its complementary oolemmal receptor IZUMO1R, in model cell lines is sufficient to support their adhesion, it fails to promote cell fusion [6-10]. Taken together, these data raise the prospect that IZUMO1 may either bind other receptor(s) or it may bind to other ancillary proteins with roles involved in oolemma adhesion and fusion. The data presented here indicated that GLIPR1L1 is one such protein and that it is required for optimal fertilization. The latter model is analogous with the concerted action of the multimeric fusogenic complexes that have been implicated in membrane fusion events as diverse as viral envelope and synaptic vesicle fusion [14, 29-32].

In regard to potential IZUMO1-interacting proteins in spermatozoa, we identified GLIPR1L1 as a key candidate in at least two high molecular weight complexes. Mouse GLIPR1L1 has a testis-enriched expression profile and undergoes extensive post-translational modifications during spermatogenesis before becoming localized to the post-acrosomal region and connecting piece of elongated spermatids and spermatozoa [21]. GLIPR1L1 is also present on the plasma membrane of at least rat, bovine, and macaque sperm and depending on species, variably anchored by a GPI linkage within lipid rafts within the membrane [24, 33]. In the bovine, GLIPR1L1 surface association appears to result from the uptake of this protein from the microvesicles that spermatozoa encounter during their maturation in the epididymis [34]. By contrast, the mouse GLIPR1L1 orthologue is acquired during spermatogenesis. It does not contain a consensus GPI anchor site and cannot be released from the sperm surface by GPI-specific phospholipase $C$ [21], confirming that the mechanism of GLIPR1L1 association with the sperm surface varies between species. Nevertheless, as an interesting example of evolutionary divergence in the means by which a protein becomes localized to an orthologous domain within sperm, our data suggest that mouse GLIPR1L1 

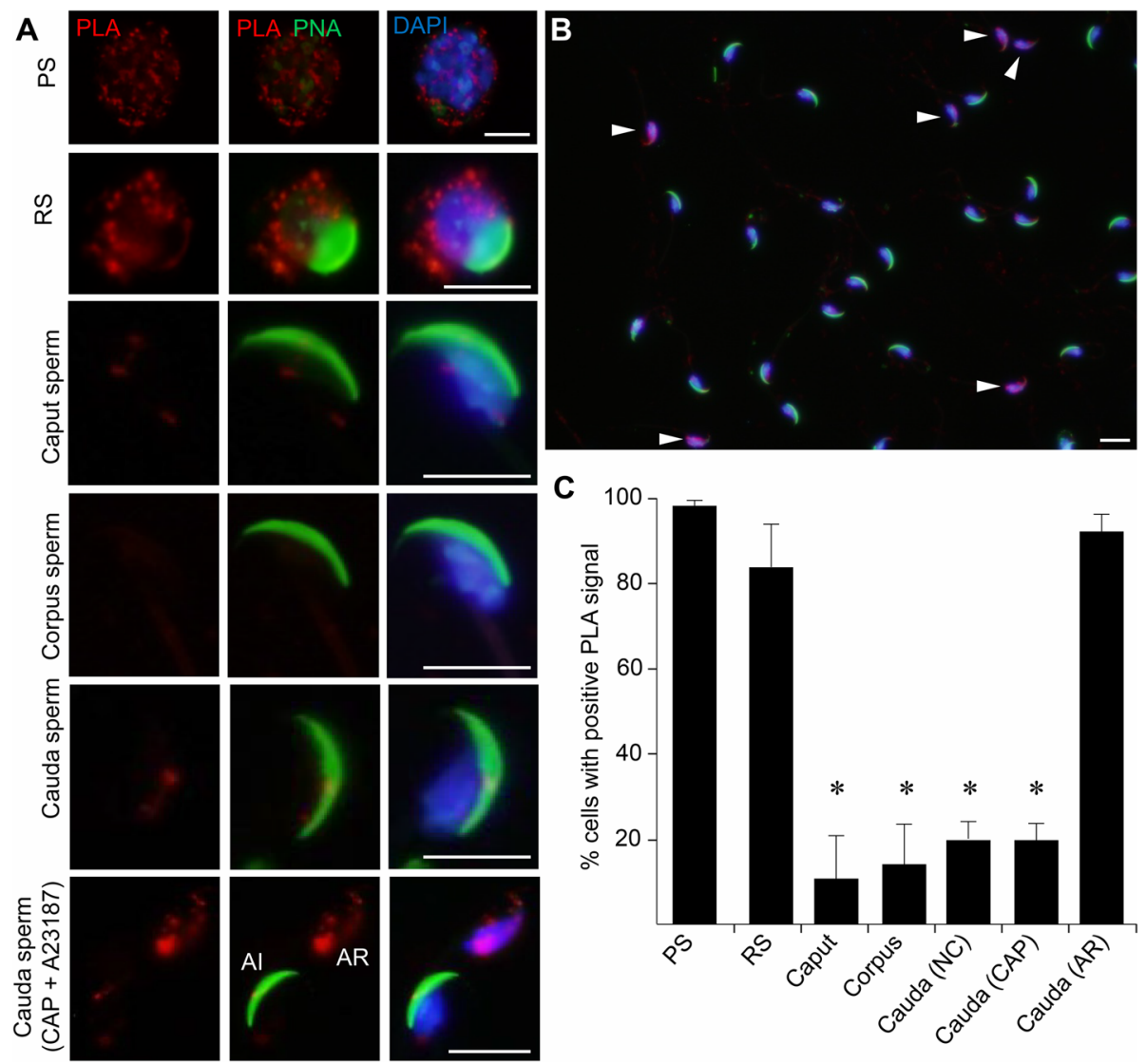

Fig. 5 Co-localization of IZUMO1 and GLIPR1L1 in developing mouse germ cells using an in situ proximity ligation assay. a The cells were counterstained with DAPI (blue) and PNA (green). This experiment was replicated three times, and representative images are shown. $\mathbf{b}$ In the case of capacitated spermatozoa, a lower magnification image is also included to highlight the differences in PLA labeling between acrosome intact and acrosome-reacted (arrowhead) spermatozoa. Scale bar $=10 \mu \mathrm{m}$. c The percentage of cells displaying PLA positive labeling was recorded. Each experiment was replicated three times and the data are expressed as the mean \pm S.E.M. ${ }^{*} P<0.05$, compared with spermatocytes. Individual data points for each replicate are provided in Additional file 6: Raw data

does partition into lipid rafts on the surface of sperm; a finding that is of importance owing to the ability of rafts to serve as platforms for the assembly of multimeric complexes that coordinate a variety of specialized functions, including fertilization [22]. While we have yet to definitively demonstrate that lipid rafts facilitate the formation and/or repositioning of GLIPR1L1-IZUMO1 complexes in mouse spermatozoa, it is noteworthy that IZUMO1 has also been independently identified as a constituent of mouse sperm lipid rafts $[17,35]$.

GLIPR1L1 is a member of the CAP superfamily which has putative roles in processes as diverse as carcinogenesis, immune tolerance, and potentially cell adhesion [20]. Of note, several additional members of the CAP family play roles in mammalian male fertility, including roles in spermatogenesis, epididymal sperm maturation, and potentially at the site of fertilization [36-39]. However, despite previous findings implicating GLIPR1L1 in sperm binding to the zona pellucida in both mouse and bovine models [21, 24], we noted only a relatively modest, non-statistically significant reduction in the abil-

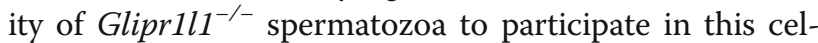
lular interaction. These data raise the prospect that deficits in sperm-zona pellucida adhesion may, at least in part, be attributed to GLIPR1L1 antibodies eliciting non-specific steric hindrance and/or masking of zona pellucida receptors. While the precise molecular function of GLIPR1L1 therefore remains to be established, data from other CAP proteins supports a putative fusogenic role and indicates that this role is most likely associated with the evolutionarily conserved CAP domain at the N-terminal half of the protein [20,40]; potentially involving the first 101 amino acids, which have been implicated previously in cell-cell adhesion [41]. Consistent with this hypothesis, the ability of GLIPR1L1 to regulate the acrosome reaction, an event in which the plasma membrane and outer acrosomal membranes fuse, is analogous to the membrane fusion processes required at the time of fertilization. Our data is also consistent with the identification of the sea squirt sperm plasma 


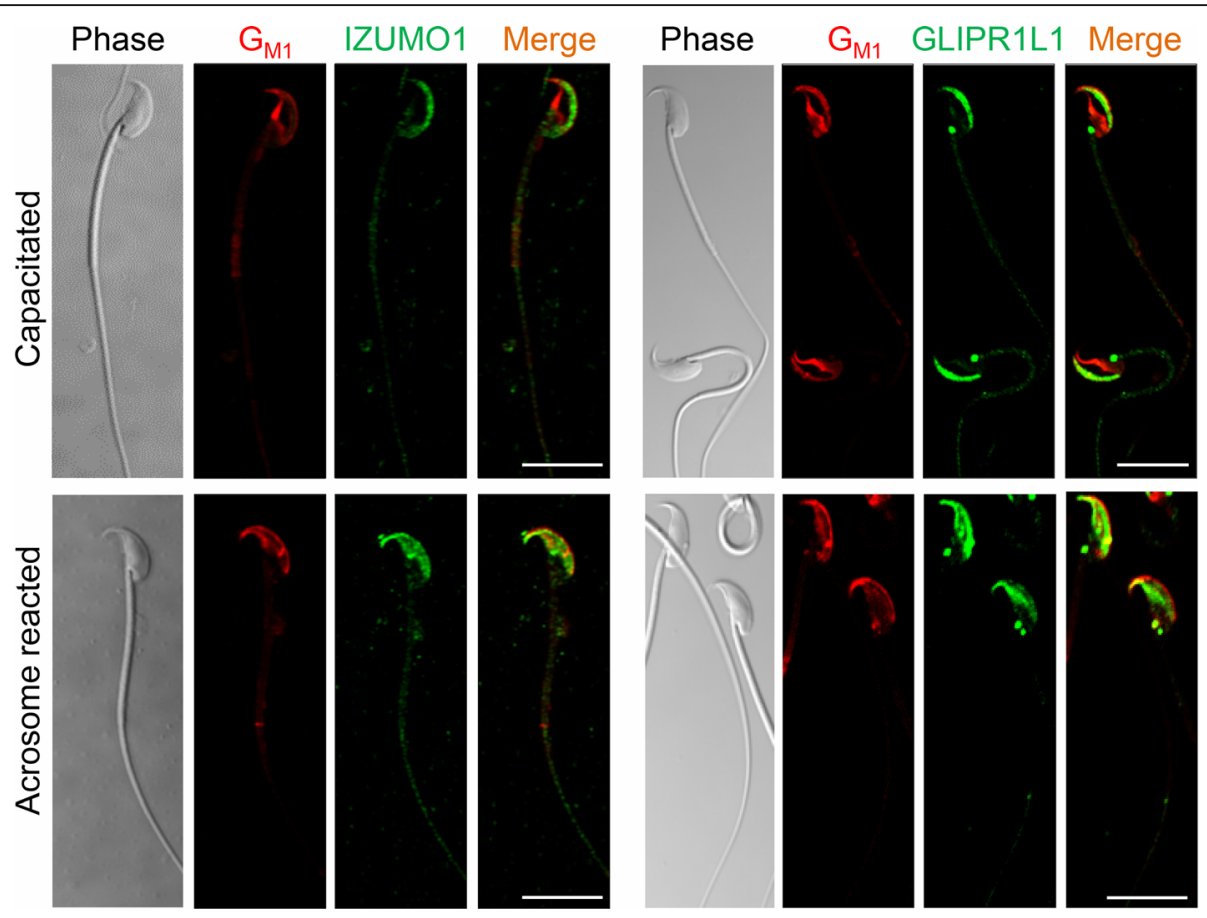

Fig. 6 IZUMO1 and GLIPR1L1 are present within the membrane raft in live capacitated spermatozoa. The presence of IZUMO1 and GLIPR1L1 was confirmed by colocalization with the raft marker, $\mathrm{G}_{\mathrm{M} 1}$. Membrane rafts were visualized in live cells by staining with Alexa Fluor 555-labeled cholera toxin B subunit (red). The cells were then fixed and labeled with the appropriate primary and Alexa Fluor 488-conjugated secondary antibodies (green). This experiment was replicated three times with a minimum of 200 spermatozoa being examined in each. Representative images are shown. Scale bar $=10 \mu \mathrm{m}$

membrane CAP proteins, HrUrabin and CiUrabin, as sperm receptors for the vitelline coat in two species of these marine invertebrates $[42,43]$, and with the ability of the mammalian CAPs, CRISP1, CRISP2, and CRISP4, to promote acrosome exocytosis in the mouse. The latter also raises the possibility that CAP domains, from a number of individual proteins, may act redundantly in acrosome function and/or fertilization [36-38, 40].

While the data demonstrates a role for GLIPR1L1 in the translocation of IZUMO1 to the post-acrosomal region prior to fertilization, the lack of co-complex formation, as illustrated by the PLA data, does not support that the IZUMO1 and GLIPR1L1 remain in association within "the" IZUMO1-containing sperm-oocyte receptor. Specifically, sperm fusion to the oocyte is known to occur at the equatorial segment. By contrast, IZUMO1GLIPR1L1 complexes are localized within the postacrosomal region. The possibility remains however that the binding and movement of IZUMO1 with GLIPR1L1 during the acrosome reaction acts to spatially restrain and coordinate both sperm binding to the oocytes and fusion between their membranes.

Importantly, the findings within this paper support the notion that the complexes we describe contain additional, as yet unidentified constituents. They also suggest that such complexes are dynamically remodeled as part of the mechanism that primes spermatozoa for their adhesion and fusion of the oolemma. This is consistent with the hypothesis that the acrosome reaction promotes extensive remodeling of the sperm architecture and culminates in the exposure of a novel set of surface proteins [12]. Although we have yet to determine how the repositioning of IZUMO1 and GLIPR1L1 is achieved, our data show that the movement of IZUMO1 is dependent on GLIPR1L1 function. These data also suggest that the sub-fertility observed in Glipr1l1 knockout male mice is, at least in part, due to the restrained distribution of IZUMO1 in knockout mice.

As an important caveat, however, despite compromising the in vitro fertilization potential of spermatozoa, the disruption of Glipr1l1 expression failed to elicit an equivalent suppression of the fertility of Glipr1l1 null males following natural mating. Indeed, Glipr1l1 knockout males sired litters of equivalent size to that of WT control males, indicating that GLIPR1L1 is not essential for male fertility. Such findings mirror those of previous studies in which numerous gene-manipulated mouse models have been shown to retain normal fertility despite the selective ablation of sperm proteins that were originally proposed as essential for fertilization based on in vitro experiments (reviewed in $[44,45]$ ). In seeking to reconcile this apparent dichotomy, it is conceivable that 

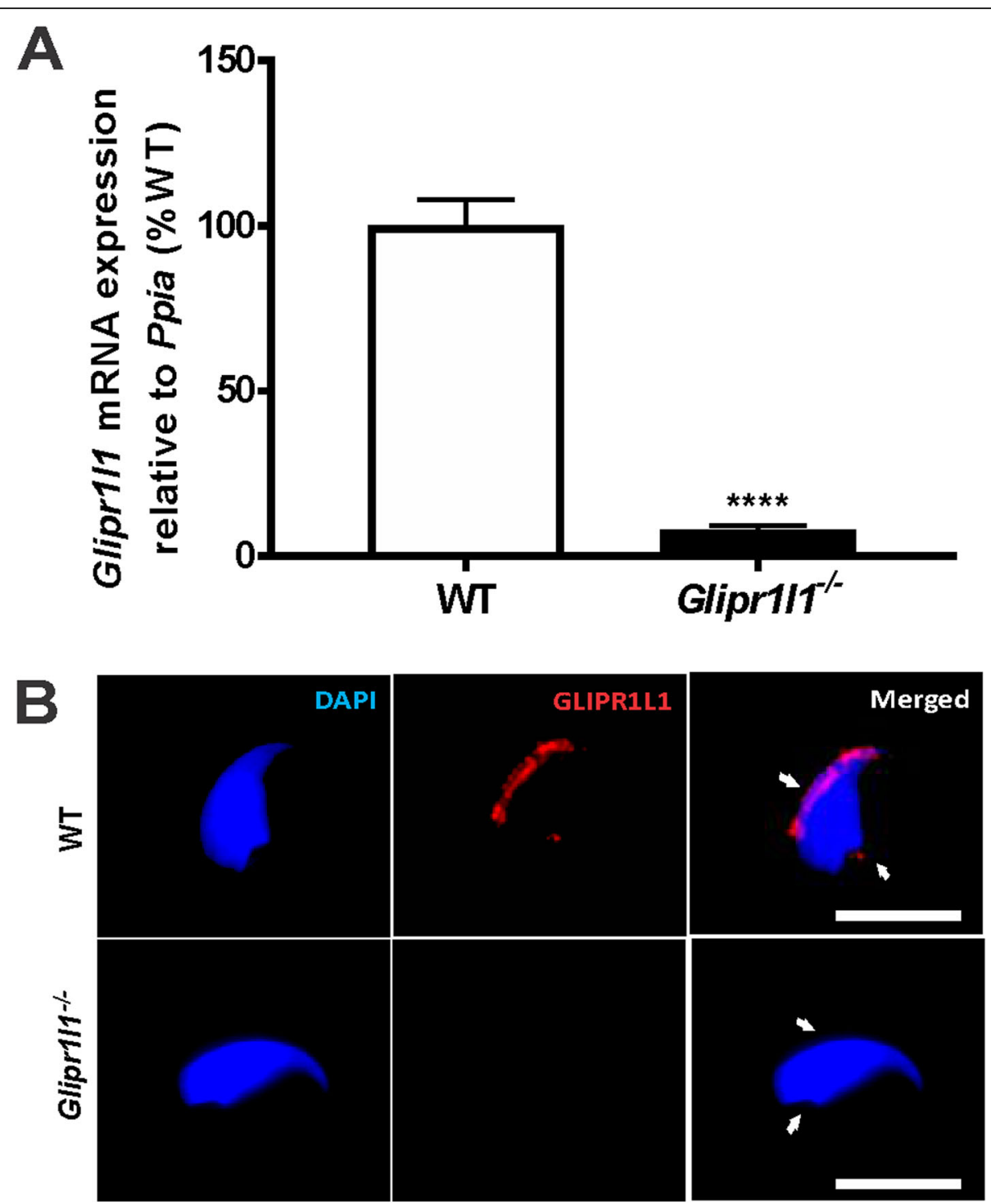

Fig. 7 Glipr1/1 expression and immunofluorescent localization in mouse sperm from wild type and Glipr1/1 ${ }^{-/-}$mice. a qPCR analysis of Glipr1/1 mRNA levels in isolated testis and germ cells from Glipr $1 / 1^{-1-}$ mice relative to wild type (WT) mice. mRNA expression levels were normalized to the housekeeping gene Ppia. This experiment was replicated three times and data is shown as mean \pm S.D., ${ }^{* * * *} P<0.0001$. Individual data points for each replicate are provided in Additional file 6: Raw data. $\mathbf{b}$ Localization of GLIPR1L1 at the sperm head and at the connecting piece. GLIPR1L1 staining (red, marked with white arrows) was observed in WT sperm and no staining was observed in the Glipr1/1 ${ }^{-/-}$sperm. In all the images, nuclear DNA was stained with DAPI (blue). This experiment was replicated three times and representative images are shown. Scale bar $=20 \mu \mathrm{m}$

knockout mice experience a genetic compensation response whereby the transcription of gene(s) related to the inactivated target is upregulated [46, 47]. Alternatively, it is possible that spermatozoa harbor multiple intrinsic oocyte receptors that work synergistically and thus impart some level of functional redundancy to key aspects of the fertilization cascade [48]. Thus, while subtle defects in sperm function may result in sub-optimal fertilization rates in an in vitro setting, these do not necessarily directly translate to reduced fertilization in vivo. Alternatively, it is possible that differences exist in the mechanistic basis by which agonists, such as the steroidal hormone progesterone, stimulate acrosomal exocytosis versus that of the physiological stimuli sperm encounter upon interaction with the oocyte vestments [49]. In any case, we noted that $\sim 17 \%$ of the spermatozoa from Glipr1l1 knockout males retained their ability to undergo an acrosome reaction (compared to 54\% WT spermatozoa), thus contributing a sufficient population of fertilization-competent spermatozoa to achieve normal rates of fertilization after natural mating. 


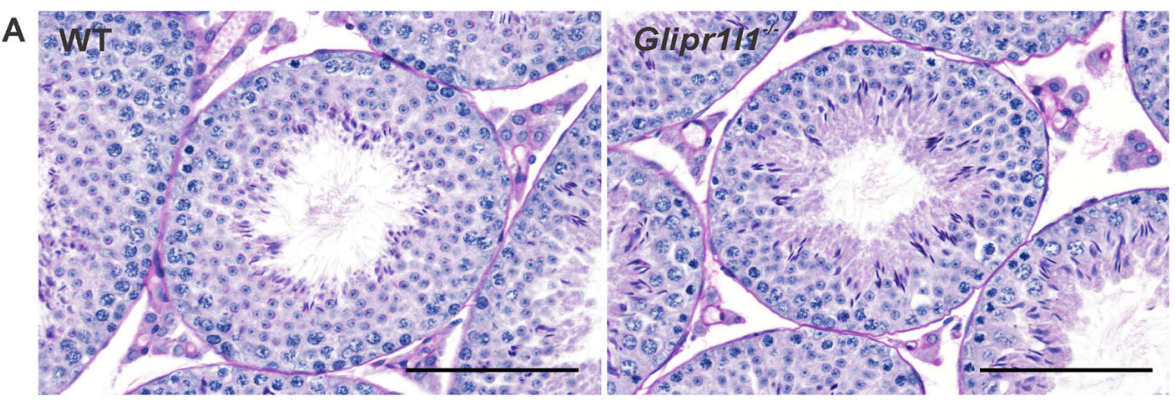

B

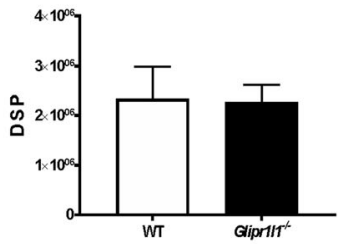

E

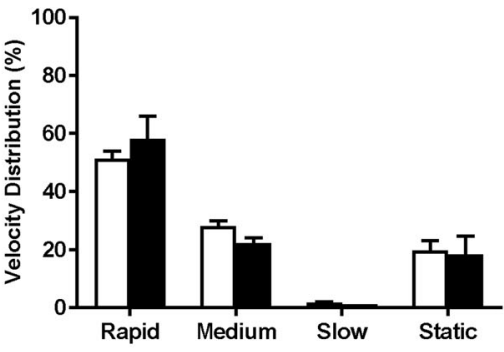

G

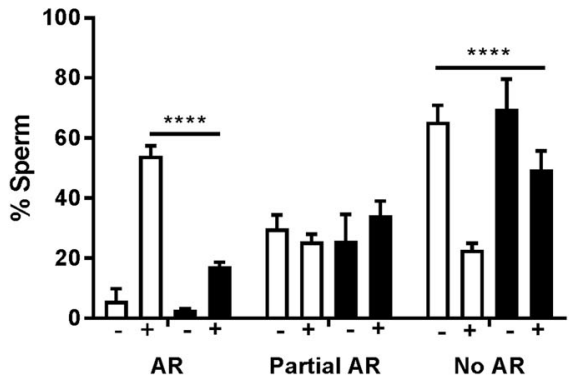

C

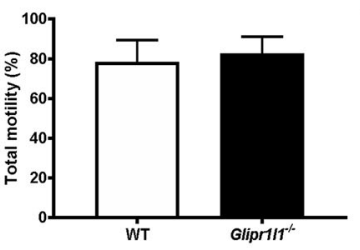

D

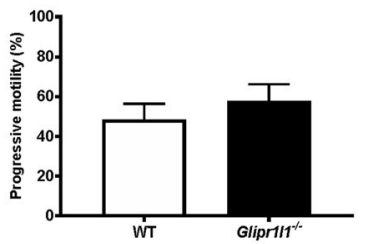

F

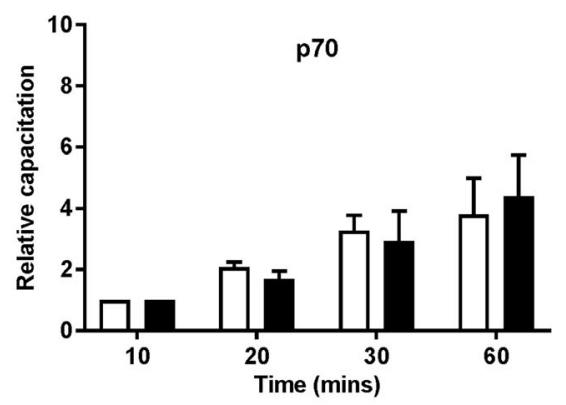

H

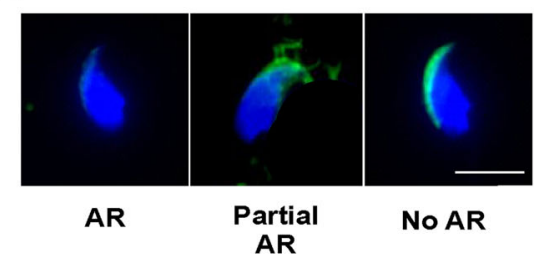

Fig. 8 Fertility assessment of Glipr $1 / 1^{-1-}$ mice. a Testicular morphology was assessed by periodic acid-Schiff (PAS) staining of the testis sections from WT and Glipr1/1 ${ }^{-1}$ mice as described in the "Methods" section. This experiment was replicated in a minimum of three mice per genotype and representative PAS staining is shown. Data are expressed as the mean \pm S.D. Scale bar $=50 \mu \mathrm{m}$. $\mathbf{b}$ Daily sperm production (DSP) within testis from WT and Glipr $1 / 1^{-1-}$ mice. This experiment was replicated in a minimum of five mice per genotype, and the data are expressed as the mean \pm S.D. Genotypes are shown on the $X$-axis, and data were shown as mean \pm S.D. c-e Computer-assisted sperm analysis demonstrates no significant difference in the motility, progressively motility, or other sperm velocity parameters between WT and Glipr $1 / 1^{-1-}$ mice. This experiment was replicated in a minimum of five mice per genotype, and the data are expressed as the mean \pm S.D. $\mathbf{f}$ As a marker of capacitation, the level of global tyrosine phosphorylation in the whole sperm population was measured. The $X$-axis depicts the length of time sperm were exposed to capacitation permissive media, as described in the "Methods" section. The relative intensity of the 70-kDa (p70) band was measured. This experiment was replicated in a minimum of six mice per genotype and the data are expressed as the mean \pm S.D. $\mathbf{g}$, $\mathbf{h}$ Assessment of the ability of Glipr $111^{-1-}$ sperm to undergo the acrosome reaction. AR indicates acrosome-reacted spermatozoa in which the entire acrosomal contents had been released from the sperm head (i.e., no PNA labeling). Partial AR indicates spermatozoa in which the acrosomal contents were incompletely shed from the sperm head (i.e., partial PNA labeling). No AR indicates spermatozoa in which the acrosomal contents are retained (i.e., complete PNA labeling). + or - indicates exposure to progesterone for the final $15 \mathrm{~min}$ of capacitation. This experiment was replicated in a minimum of four mice per genotype with a minimum of 200 spermatozoa being examined in each replicate. Data are expressed as the mean $\pm S . D$. ${ }^{*} P<0.05$, ${ }^{*} P<0.01,{ }^{* *} P<0.001$. Individual data points for each replicate are provided in Additional file 6: Raw data 


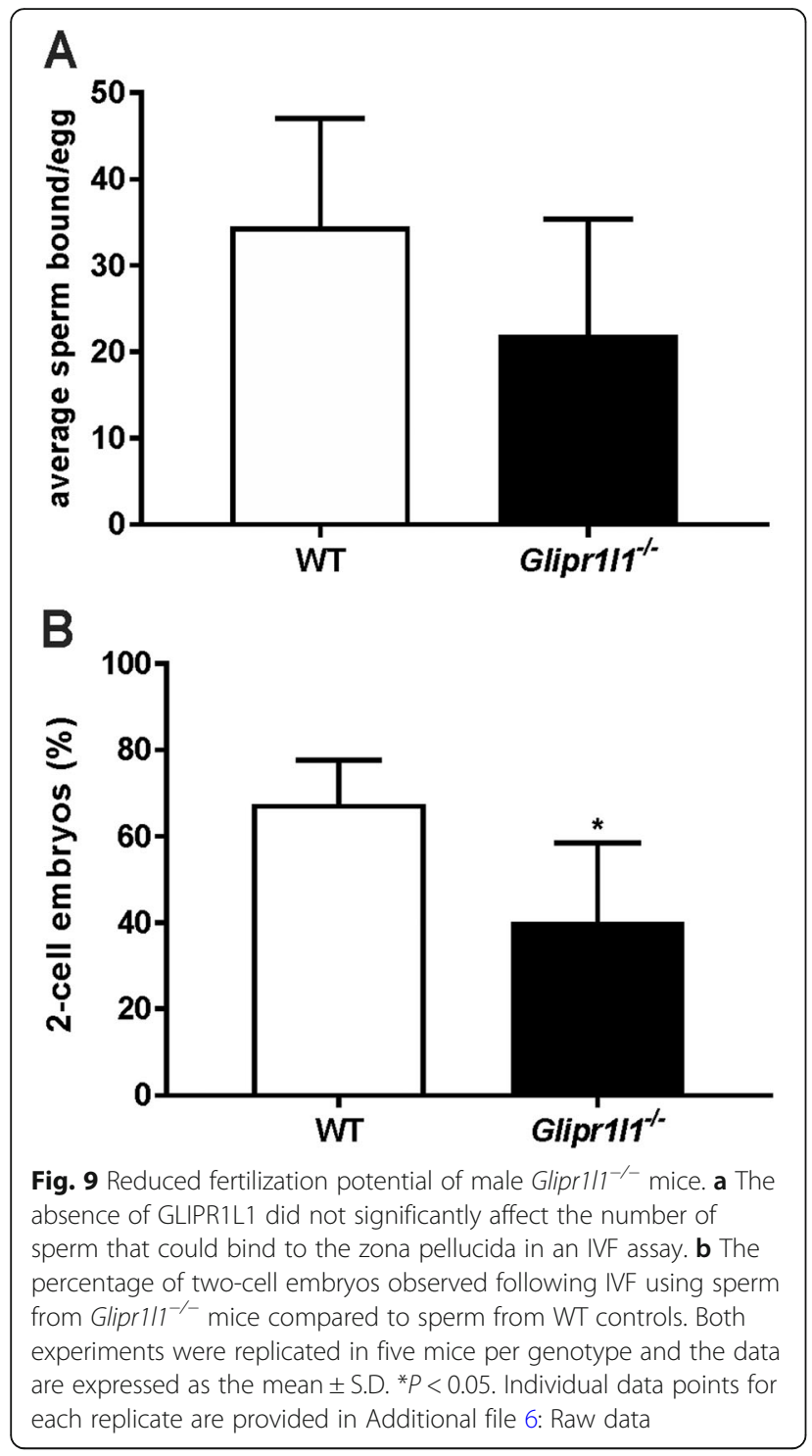

\section{Conclusion}

In conclusion, the present study supports a growing body of evidence that mammalian spermatozoa are reliant on multimeric protein complexes to engage in several critical aspects of the fertilization cascade, including that of oolemmal adhesion and fusion [50]. At least some of these complexes contain IZUMO1 and GLIPR1L1 and identify CAP proteins as evolutionary conserved plasma membrane receptors with roles in sperm function and fertilization.

\section{Methods}

\section{Reagents}

Unless specified, chemical reagents were obtained from Sigma (St. Louis, Mo, USA). Antibodies used are outlined in Additional file 5: Table S1 as online in the supplemental material.
Isolation and preparation of mouse spermatozoa

All experimental procedures were carried out with the approval of the University of Newcastle Animal Care and Ethics Committee (A-2013-322) or the Monash University Biological Sciences Animal Ethics Committee (BSCI/ 2017/30) and conformed to the National Health and Medical Research guidelines for animal handling. Inbred Swiss mice were obtained from the Newcastle Universities Central Animal House. Mice at the Newcastle University location were housed under a controlled lighting regime (16L:8D) at $21-22^{\circ} \mathrm{C}$. Mice at Monash University site were housed under a controlled lighting regime (12L:12D) at $18-22^{\circ} \mathrm{C}$. All mice were supplied with food and water ad libitum.

For the oocyte receptor complex identification, adult male mice ( $>8$ weeks old) were euthanized, and their epididymides and testes were removed and dissected free of fat and overlying connective tissue. Caudal spermatozoa were collected by backflushing [51] after which the perfusate was deposited into modified Biggers, Whitten, and Whittingham media (BWW [52];) or Modified Tyrode 6 media (MT6 [53];). Where indicated, negative control (non-capacitated) incubations were conducted using non-capacitation medium prepared without $\mathrm{NaHCO}_{3}$ but with additional $\mathrm{NaCl}$ incorporated to maintain an osmolarity of $300 \mathrm{mOsm} / \mathrm{kg}$. The formation of bicarbonate in these samples was prevented by capping the tubes throughout the incubation at $37^{\circ} \mathrm{C}$ in $5 \% \mathrm{CO}_{2}: 95 \%$ air. Positive control (capacitated) incubations were conducted in media supplemented with $1 \mathrm{mM}$ pentoxifylline (ptx) and $1 \mathrm{mM}$ dibutyryl cyclic adenosine monophosphate (dbcAMP). These treatments have been demonstrated to suppress and promote sperm capacitation, respectively, the latter being defined by tyrosine phosphorylation, hyperactivation, and zona binding [54].

Following sperm collection, the sperm concentration was determined and the cells were diluted as required. Spermatozoa were then assessed for motility (see below) and the non-capacitated samples used immediately. Alternatively, capacitated spermatozoa were prepared by incubation for up to $60 \mathrm{~min}$ at $37^{\circ} \mathrm{C}$ in $5 \% \mathrm{CO}_{2}$ : $95 \%$ air. At regular intervals throughout the incubation, sperm suspensions were gently mixed to prevent settling, and at the end of the incubation, sperm vitality and motility were again assessed. Neither parameter was adversely affected by any of the treatments reported in this study.

To prepare caput and corpus spermatozoa, the appropriate epididymal segment was dissected and placed in a $500-\mu \mathrm{l}$ droplet of BWW medium. Multiple incisions were then made in the tissue with a razor blade and spermatozoa gently washed into the medium with mild agitation. The resultant cell suspension was layered over $27 \%$ Percoll and centrifuged $(400 \times g$ for $15 \mathrm{~min})$ [55, 56]. The pellet, consisting of $>95 \%$ pure spermatozoa, was 

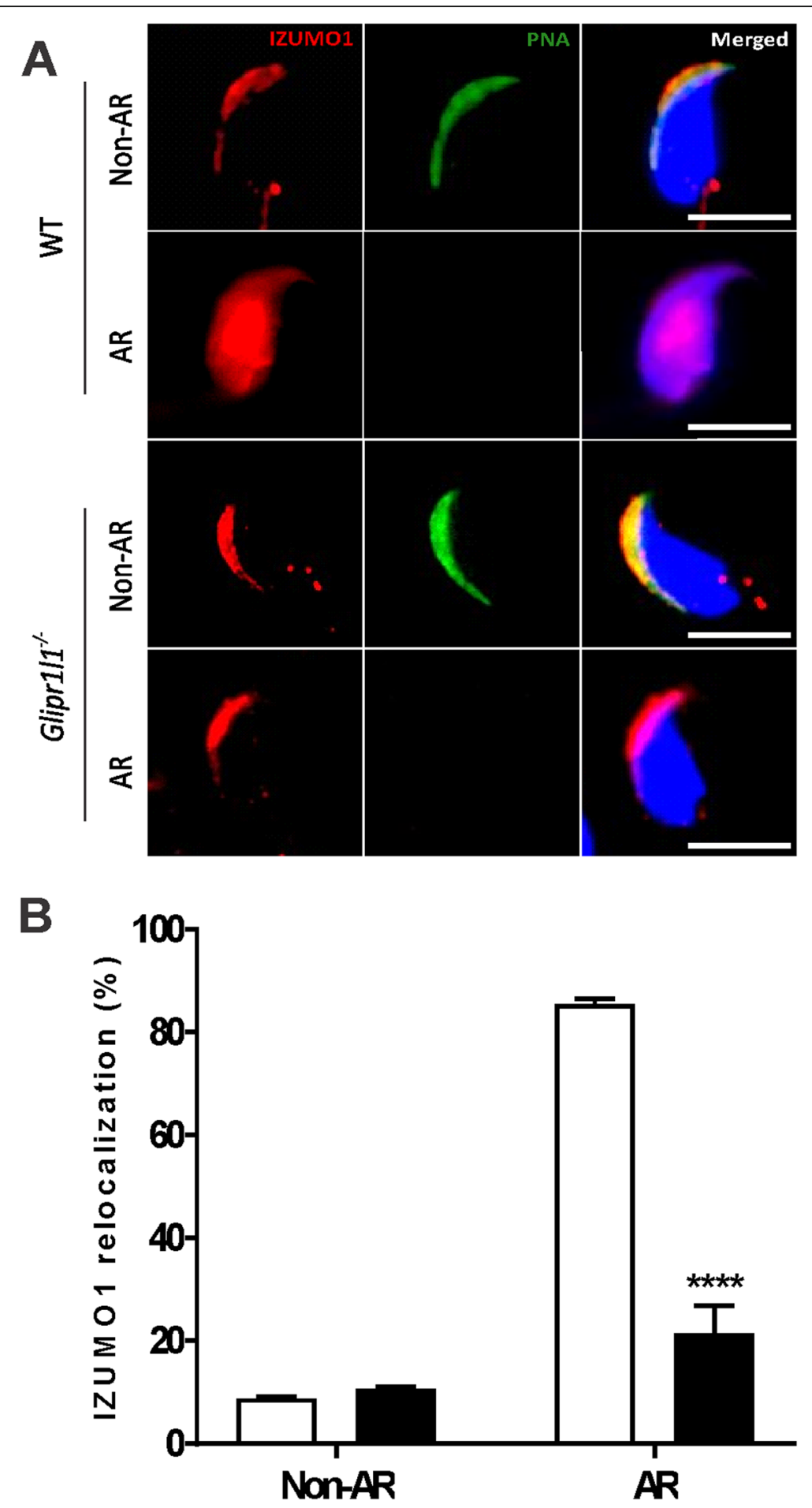

Fig. 10 GLIPR1L1 loss disrupts IZUMO1 redistribution during the acrosome reaction. a Sperm were stained for IZUMO1 localization and the acrosome was labeled with PNA (green), while DNA was stained with DAPI (blue). Scale bar $=20 \mu \mathrm{m}$. b The percentage of sperm that displayed IZUMO1 relocalization was scored in non-acrosome-reacted (Non-AR) and acrosome-reacted (AR) sperm from WT and Glipr $1 / 1^{-/-}$mice. This experiment was replicated five times with a minimum of 200 spermatozoa being examined in each. Representative images are shown. ${ }^{*} P<0.05$, ${ }^{* *} P<0.01,{ }^{* *} P<0.001$. Individual data points for each replicate are provided in Additional file 6: Raw data 
washed by gentle centrifugation $(400 \times g$ for $2 \mathrm{~min})$ to remove excess Percoll and then resuspended in fresh BWW medium and counted as described above. Testicular spermatozoa were prepared by decapsulating testes, making multiple incisions in the tissue and allowing the cells to gently disperse into the medium with mild agitation. They were then isolated by Percoll gradient centrifugation as described above.

\section{Knockout mouse model production}

The Glipr1l1 knockout mouse line (Glipr1l1 $\left.{ }^{-/}\right)$was generated by the Australian Phenomics Network Monash University Node by modifying Glipr1l1 using CRISPR/ Cas9 technology. Briefly, Glipr1l1 was modified at exon 1 (ENSMUSE00000640359) by the guide RNA (gRNA) sequence: forward-TCCTAGGGTGCCAACTATCA and reverse-TGATAGTGCCTAGGCTTTAA, which includes the scaffolding required to form a complex with the CRISPR-associated nuclease Cas9. The resulting Cas9/ gRNA complex bound to the protospacer adjacent motif (PAM) and cleaved the double-stranded DNA three nucleotides upstream of the PAM site leaving blunt ends. This break in the DNA stimulated an imprecise nonhomologous end joining repair which resulted in a 7-bp (ACTATCA) deletion in exon 1 of the Glipr1l1 gene. This resulted in a truncated mRNA containing exon 1, which encoded the first $39 \mathrm{~N}$-terminal amino acids of the GLIPR1L1 protein (Additional file 2: Figure S2A-B). Gene ablation was assessed using $\mathrm{qPCR}$ and immunohistochemistry as outlined below.

Total RNA from the testis and isolated germ cells were extracted using TRIzol reagent (Life Technologies, USA) and converted to cDNA using SuperScriptIII reverse transcriptase and oligo dT (Life Technologies) $(n=3$ per genotype). The Glipr1l1 transcript levels in testis of Glipr1l1 $1^{-/}$ mice were assessed relative to wild-type littermates by qPCR in SYBR Select Master Mix (Applied Biosystems, USA). All PCRs were performed in the Quant Studio 3 (Applied Biosystems, USA) qPCR system: $95^{\circ} \mathrm{C}, 10 \mathrm{~min}$ for one cycle; $95^{\circ} \mathrm{C}, 15 \mathrm{~s} ; 60^{\circ} \mathrm{C}$ for $1 \mathrm{~min}$ for 40 cycles. Different expression data was analyzed using the $2^{\Delta \Delta C T}$ method and normalized against the housekeeping gene Ppia (Mm02342429). The following primers for Glipr1l1 were used: forward 5 '-CCAAGGCATTCGGCAAAGAT$3^{\prime}$ and reverse 5'-ATTCATATCAGCTGCCGGGG-3'. The expected size of the PCR product was 150 base pairs. Statistical analysis was performed using two-tailed unpaired Student's $t$ test.

\section{Induction of acrosomal exocytosis}

To assess whether protein localization was influenced by the acrosomal status of spermatozoa, acrosomal exocytosis was induced either by incubation of capacitated cells in $2.5 \mu \mathrm{M}$ calcium ionophore $\mathrm{A} 23187$ or $15 \mu \mathrm{M}$ progesterone as previously described [57]. To identify live sperm, the sperm suspensions were then washed, resuspended in hypo-osmotic swelling (HOS) medium [58], and incubated for an additional $1 \mathrm{~h}$. Following incubation, the cells were sequentially labeled with the appropriate primary and Alexa Fluor 488-conjugated secondary antibodies as indicated below. Spermatozoa were then labeled with either $1 \mu \mathrm{g} / \mathrm{ml}$ PNA-TRITC (Sigma, L3766) or PNA-FITC (Sigma, L7381) and prepared for microscopy as outlined below.

\section{Immunolocalization of target proteins}

Sperm suspensions were fixed in $4 \%$ paraformaldehyde (PFA) and prepared for immunolocalization of candidate proteins using standard protocols [59]. Alternatively, target proteins were colocalized with lipid rafts via dual labeling with Alexa Fluor 555-labeled B subunit of cholera toxin (CTB), which labels the raft marker $\mathrm{G}_{\mathrm{M} 1}$ gangliosides, as previously described $[23,60]$. Protein colocalization was also assessed via in situ primary ligation assays (PLA) in accordance with the manufacturers' instructions (OLINK Biosciences, Uppsala, Sweden). Briefly, male germ cells and spermatozoa were fixed in $4 \%$ PFA and coated onto poly-L-lysine slides overnight at $4{ }^{\circ} \mathrm{C}$. These cells were then blocked before target proteins were sequentially labeled with IZUMO1 and GLIPR1L1 primary antibodies followed by appropriate secondary antibodies conjugated to complementary synthetic oligonucleotides (PLA probes). After enzymatic ligation and amplification, target proteins residing within a maximum of $30-40 \mathrm{~nm}$ were identified by the production of discrete fluorescent foci $[25,61]$. In all cases, fluorescent labeling of cells was visualized with an Axio Imager A1 fluorescence microscope (Carl Zeiss Microimaging Inc., Thornwood, NY, USA) and pictures were taken using an Olympus BX53 microscope (Olympus America, Center Valley, PA, USA) equipped with an Olympus DP80 camera mounted with a 40×/0.95 UPlanSApo Olympus objective.

\section{Blue native polyacrylamide gel electrophoresis}

Populations of non-capacitated, capacitated, and acrosomereacted spermatozoa $\left(1 \times 10^{6}\right.$ cells $\left./ \mathrm{ml}\right)$ were gently pelleted $(300 \times g$ for $5 \mathrm{~min})$ and resuspended in native protein lysis buffer consisting in preparation for resolution of protein complexes via one-dimensional blue native PAGE (1D BNPAGE) [25, 26]. After completion of electrophoresis, gels were stained sequentially with Coomassie G250 then silver stained (to detect less abundant proteins). Alternatively, the gels were prepared for either western blotting or twodimensional BN-PAGE (2D BN-PAGE) [19, 25, 62, 63].

To verify protein interactions, a reciprocal coimmunoprecipitation strategy was employed [19], whereby protein $\mathrm{G}$ magnetic beads (Millipore, Billerica, MA, USA) were conjugated with $5 \mu \mathrm{g}$ of the appropriate antibody at $4{ }^{\circ} \mathrm{C}$ overnight with constant mixing. 
Following conjugation, the antibody-bead complexes were washed before being covalently cross-linked by incubation in DTSSP (Thermo Fisher Scientific; $15 \mathrm{mM}, 2 \mathrm{~h}$ at $4{ }^{\circ} \mathrm{C}$ ). The cross-linking reaction was quenched using $1 \mathrm{M}$ Tris, and the conjugated beads were washed before being incubated with approximately $100 \mu \mathrm{g}$ of sperm lysates that had been pre-cleared with non-conjugated beads to limit nonspecific interactions. After an overnight incubation at $4{ }^{\circ} \mathrm{C}$ with constant mixing, the beads were washed three times prior to elution of bound proteins by incubation in SDS loading buffer for $5 \mathrm{~min}$. Precipitated proteins were resolved on $4-20 \%$ polyacrylamide gels and prepared for either silver staining or immunoblotting.

\section{Western and far-western blotting}

Proteins resolved by either 1D or 2D BN-PAGE were transferred onto nitrocellulose membranes using conventional western blotting techniques [64]. To detect proteins of interest, membranes were blocked then sequentially probed with appropriate primary and secondary antibodies using standard protocols [65] before being visualized using an enhanced chemiluminescence (ECL) kit (GE Healthcare) according to the manufacturer's instructions. To detect native protein complexes with affinity for oolemmal proteins, 1D BN-PAGE gels were transferred to nitrocellulose membranes, blocked, and prepared for far-western blotting with biotin-labeled preparations of oocyte lysates using protocols modified from $[25,26]$. Briefly, oocyte proteins were biotinylated by incubation of denuded mouse oocytes (approximately $100 /$ experiment) in $1 \mathrm{mg} / \mathrm{ml}$ sulfo-NHS-LC-biotin at $37^{\circ} \mathrm{C}$ for $30 \mathrm{~min}$. The biotin reaction was quenched by washing the oocytes in $100 \mathrm{mM}$ glycine. Oocytes were lysed by incubation in $10 \mathrm{mM}$ CHAPS for $1 \mathrm{~h}$ at $4{ }^{\circ} \mathrm{C}$. This preparation was then incubated with the BN-PAGE western blots overnight at $4{ }^{\circ} \mathrm{C}$ on an orbital rotator. Membranes were then washed three times in TBST before incubation with HRP-conjugated streptavidin (diluted 1: 4000 in $1 \% \mathrm{w} / \mathrm{v}$ BSA/TBST) for $1 \mathrm{~h}$. Labeled complexes were then detected using ECL as described above.

\section{Protein identification from BN-PAGE}

Protein complexes with affinity for homologous oolemmal proteins were carefully excised and prepared for mass spectrometry (MS) analysis at the Australian Proteome Analysis Facility using a one-dimensional nanoliquid chromatography electrospray ionization MS/MS interface, as previously described $[26,65]$. Peptide data were searched using Mascot (Matrix Science Ltd., London, UK). Peaklists were searched against Mus musculus in the SwissProt database with the following search parameters: maximum of one missed trypsin cleavage, cysteine carbamidomethylation, methionine oxidation, and a maximum 0.2-Da error tolerance in both the MS and MS/MS data. High-confidence positive identifications were based on a minimum of two matching peptides and were confirmed or qualified by operator inspection of the spectra and search results.

\section{Knockout mouse fertility analysis}

The effect of Glipr1l1 ablation on male mouse fertility was assessed using our previously published strategy [66]. All assays, including breeding trials, were conducted using 10-12-week-old mice ( $n=5$ per genotype), a time at which male fertility should be maximal. Briefly, the daily sperm production (DSP) within the testis and total epididymal sperm content were assessed in WT and $\mathrm{KO}$ males as previously described $(n=5$ per genotype) [36]. Sperm motility parameters, including total sperm motility, progressive motility, and sperm velocity distribution (rapid, medium, slow, and static) parameters, were measured using a Hamilton-Thorne (MouseTraxx, USA) computer-assisted sperm analyzer (CASA) as described previously [67]. Sperm from cauda epididymis and vas deferens were collected using the backflushing technique. The spermatozoa suspension was equilibrated in vitro for $15 \mathrm{~min}$ and loaded into a CASA chamber ( $80 \mu \mathrm{m}$ depth) for analysis. Sperm motility was classified as rapid motility $(>35 \mu \mathrm{m} / \mathrm{s})$, medium motility $(10-35 \mu \mathrm{m} / \mathrm{s})$, slow motility $(<10 \mu \mathrm{m} / \mathrm{s})$, and static $(0 \mu \mathrm{m} / \mathrm{s})$ [67]. A minimum of 1000 sperm were measured in triplicate.

The ability of sperm to undergo the acrosome reaction was assessed and scored using PNA staining of the acrosome [37] following incubation with $15 \mu \mathrm{M}$ progesterone. A spontaneous acrosome reaction control (buffer only) was included to monitor baseline reactivity.

The ability of sperm to capacitate was assessed using global tyrosine phosphorylation as a biomarker using the method outlined in $\mathrm{Hu}$ et al. [36] ( $n=6$ per genotype). For western blotting, sample loading was normalized using the endogenously phosphorylated hexokinase band $(130 \mathrm{kDa})$.

The ability of sperm to interact with oocytes was measured using zona binding and IVF assays as described previously $[36,68]$ ( $n=5$ per genotype). For IVF, cumulus-oocyte complexes collected from super-ovulated females were placed in human tubal fluid (HTF) medium (Merck) under mineral oil at $37^{\circ} \mathrm{C}$ for $15-30 \mathrm{~min}$. A sample of $2 \times 10^{5} \mathrm{ca}-$ pacitated sperm from each male were incubated with a separate clutch of cumulus-oocyte complexes. Gametes were left to achieve fertilization for $4 \mathrm{~h}$ at $37^{\circ} \mathrm{C}$ in an atmosphere of $5 \% \mathrm{CO}_{2}$. Potential zygotes were then washed three times in HTF medium and transferred to a drop of pre-warmed potassium-supplemented simplex optimized medium (KSOM) to mature to the two-cell stage overnight. Successful fertilization was assessed 24 $\mathrm{h}$ post-fertilization by counting the percentage of twocell embryos relative to total oocytes used. For the zona 
binding assay, cumulus-oocyte complexes isolated as above were treated with hyaluronidase for $1 \mathrm{~min}$ to remove $\mathrm{cu}$ mulus cells and stored in high salt storage medium at $4{ }^{\circ} \mathrm{C}$ until use [68]. After three washes in PBS, salt stored oocytes were transferred to BWW medium and co-incubated with a sample of $2 \times 10^{5}$ capacitated sperm for $20 \mathrm{~min}$ at $37^{\circ} \mathrm{C}$. Oocytes were washed in PBS and transferred to slides to count the number of sperm bound. A total of $4-8$ oocytes were used per replicate.

\section{Statistical analysis}

Data were analyzed using GraphPad Prism Version 7.0 (GraphPad Software). Statistical differences between groups were evaluated using two-way ANOVA, TukeyKramer HSD, and unpaired Student's $t$ tests. Significant differences were indicated with ${ }^{*} P<0.05$, ${ }^{* *} P<0.01$, ${ }^{* * * *} P<0.001$, and ${ }^{* * * * *} P<0.0001$. Densitometry analysis was carried from western blot band intensity in Image software v1.52i (National Institutes of Health, USA) and then analyzed by two-way ANOVA.

\section{Supplementary information}

Supplementary information accompanies this paper at https://doi.org/10. 1186/s12915-019-0701-1.

Additional file 1: Figure S1. Proximity ligation assays (PLA) were used to assess the interaction of IZUMO1 and GLIPR1L1. Shown are representative images of negative controls, which included the labeling of spermatozoa with paired antibodies against proteins that would not be expected to interact with IZUMO1; (A) IZUMO1 and tubulin, and (B) IZUMO1 and acrosin. (C) Additional controls included the substitution of one of the primary antibodies for buffer alone (IZUMO1 only). After PLA labeling, spermatozoa were counterstained with PNA (green) and DAPI (blue). Scale bar $=10 \mu \mathrm{m}$.

Additional file 2: Figure S2. Glipr1/1 CRISPR/Cas9 genome editing strategy. (A) Schematic representation of exons 1-5 of mouse Glipr1/1 gene. The guide RNA sequence (highlighted in red) followed by protospacer adjacent motif (PAM) sequence (highlighted in blue) is represented in the dotted box. (B) The 7 bp (ACTATCA) deletion (highlighted in the red box) in the wild-type Glipr1/1 results in a frame-shift (marked in red dotted line) mutation and a subsequent premature stop codon (highlighted in red) which generates a $4 \mathrm{kDa}$ truncated GLIPR1L1 protein.

Additional file 3: Figure S3. Fecundity and morphometry in WT and Glipr1/1-/- mice. (A) Average litter size from WT mice mated with WT female mice and Glipr 1/1-/- male mice mated with WT female mice. (B) Comparable body weight $(\mathrm{g})$ and $(\mathrm{C})$ testis weight $(\mathrm{g})$ were observed between WT and Glipr1/1-/- mice. This experiment was replicated in a minimum of 4-5 mice per genotype and the data are expressed as the mean \pm S.D

Additional file 4: Figure S4. The loss of GLIPR1L1 does not impact sperm capacitation. The level of total tyrosine phosphorylation was assessed by measuring a band with molecular weight of $110 \mathrm{kDa}$ (p110). Representative western blotting results are depicted on the bottom row. The most intense band towards the top of each blot is the constitutively phosphorylated protein hexokinase $(130 \mathrm{kDa})$ which acted as a loading control. This experiment was replicated in a minimum of six mice per genotype and the data are expressed as the mean \pm S.D.

Additional file 5: Table S1. List of antibodies used.

Additional file 6. Raw data. This file contains raw data with individual data points or replicates for Figures $5 c$; 7a; $8 a-g$; $9 a, b$; $10 b$ (i.e. those experiments in which $n<6$ ).

\section{Abbreviations}

ADAM: A disintegrin and metalloprotease domain; BN-PAGE: Blue nativepolyacrylamide gel electrophoresis; BSA: Bovine serum albumin; BWW: Biggers, Whitten, and Whittingham media; CAP: Cysteine-rich secretory proteins, antigen 5, and pathogenesis-related 1 proteins; dbcAMP: Dibutyryl cyclic adenosine monophosphate; GLIPR1L1: GLI pathogenesis-related 1 like 1; HEK293: Human embryonic kidney 293; HOS: Hypo-osmotic swelling; HTF: Human tubal fluid; IZUMO1: Izumo sperm-egg fusion 1;

IZUMO1R: IZUMO1 receptor, JUNO; MS: Mass spectrometry; PBS: Phosphate buffered saline; PFA: Paraformaldehyde; PLA: Proximity ligation assay; PNA: Peanut agglutinin

\section{Acknowledgements}

The authors gratefully acknowledge the intellectual input and excellent technical assistance of Dr. Gerard Gibbs and Dr. Duangporn Jamsai.

\section{Authors' contributions}

The hypotheses and experimental design for this research was developed by $A G, R J A, B N$, and $M O^{\prime} B$. Experiments were undertaken by $A G, A A, D J M, A O^{\prime} C$, and $\mathrm{BH}$. All authors were involved in data analysis. $A G, R J A, B N$, and $M O^{\prime} B$ were involved in figure production and writing the first draft of the manuscript. The final manuscript was approved by all authors.

\section{Funding}

This study was supported by funding from the NHMRC to MKOB (APP1058356) and BN (APP1147932), and Australian Research Council funding to BN (FT140101368).

\section{Availability of data and materials}

All data generated during this study are included in this published article and its additional files. Raw data for Figs. 5c, 7a, 8a-9, 9a, b, and 10b (i.e., those experiments in which $n<6$ ) can be found in Additional file 6: Raw data.

\section{Ethics approval and consent to participate}

All experimental procedures were conducted with the approval of the University of Newcastle Animal Care and Ethics Committee (A-2013-322) or the Monash University Biological Sciences Animal Ethics Committee (BSCl/ 2017/30) and conformed to the National Health and Medical Research guidelines for animal handling.

\section{Consent for publication}

All authors have given consent for publication.

\section{Competing interests}

The authors declare that they have no competing interests.

Received: 26 June 2019 Accepted: 19 September 2019

Published online: 31 October 2019

\section{References}

1. Nixon B, Aitken RJ, McLaughlin EA. New insights into the molecular mechanisms of sperm-egg interaction. Cell Mol Life Sci. 2007;64(14):1805-23.

2. Satouh $Y$, Ikawa M. New insights into the molecular events of mammalian fertilization. Trends Biochem Sci. 2018:43(10):818-28.

3. Inoue N, Ikawa M, Isotani A, Okabe M. The immunoglobulin superfamily protein Izumo is required for sperm to fuse with eggs. Nature. 2005; 434(7030):234-8.

4. Satouh $Y$, Inoue $N$, Ikawa M, Okabe M. Visualization of the moment of mouse sperm-egg fusion and dynamic localization of IZUMO1. J Cell Sci. 2012;125(Pt 21):4985-90.

5. Jean C, Haghighirad F, Zhu Y, Chalbi M, Ziyyat A, Rubinstein E, Gourier C, Yip P, Wolf JP, Lee JE, et al. JUNO, the receptor of sperm IZUMO1, is expressed by the human oocyte and is essential for human fertilisation. Hum Reprod. 2019;34(1):118-26.

6. Bianchi E, Doe B, Goulding D, Wright GJ. Juno is the egg Izumo receptor and is essential for mammalian fertilization. Nature. 2014;508(7497):483-7.

7. Kato K, Satouh Y, Nishimasu H, Kurabayashi A, Morita J, Fujihara Y, Oji A, Ishitani R, Ikawa M, Nureki O. Structural and functional insights into IZUMO1 recognition by JUNO in mammalian fertilization. Nat Commun. 2016;7:12198. 
8. Inoue N, Hamada D, Kamikubo H, Hirata K, Kataoka M, Yamamoto M, Ikawa M, Okabe M, Hagihara Y. Molecular dissection of IZUMO1, a sperm protein essential for sperm-egg fusion. Development. 2013;140(15):3221-9.

9. Chalbi M, Barraud-Lange V, Ravaux B, Howan K, Rodriguez N, Soule P, Ndzoudi A, Boucheix C, Rubinstein E, Wolf JP, et al. Binding of sperm protein Izumo1 and its egg receptor Juno drives $C d 9$ accumulation in the intercellular contact area prior to fusion during mammalian fertilization. Development. 2014;141(19):3732-9.

10. Inoue N, Hagihara Y, Wright D, Suzuki T, Wada I. Oocyte-triggered dimerization of sperm IZUMO1 promotes sperm-egg fusion in mice. Nat Commun. 2015;6:8858

11. Ellerman DA, Pei J, Gupta S, Snell WJ, Myles D, Primakoff P. Izumo is part of a multiprotein family whose members form large complexes on mammalian sperm. Mol Reprod Dev. 2009;76(12):1188-99.

12. Okabe M. The cell biology of mammalian fertilization. Development. 2013; 140(22):4471-9.

13. Salsman J, Top D, Barry C, Duncan R. A virus-encoded cell-cell fusion machine dependent on surrogate adhesins. PLoS Pathog. 2008;4(3):e1000016.

14. Harrison SC. Mechanism of membrane fusion by viral envelope proteins. Adv Virus Res. 2005;64:231-61.

15. Roche SR, Félix A, Gaudin Y, Bressanelli S. Structure of the Prefusion Form of the Vesicular Stomatitis Virus Glycoprotein G. Science. 2007;315(5813):843-8.

16. Xu Y, Liu Y, Lou Z, Qin L, Li X, Bai Z, Pang H, Tien P, Gao GF, Rao Z. Structural basis for coronavirus-mediated membrane fusion. Crystal structure of mouse hepatitis virus spike protein fusion core. J Biol Chem. 2004;279(29):30514-22.

17. Miranda PV, Allaire A, Sosnik J, Visconti PE. Localization of low-density detergent-resistant membrane proteins in intact and acrosome-reacted mouse sperm. Biol Reprod. 2009;80(5):897-904.

18. Vjugina U, Evans JP. New insights into the molecular basis of mammalian sperm-egg membrane interactions. Front Biosci. 2008;13:462-76.

19. Dun MD, Anderson AL, Bromfield EG, Asquith KL, Emmett B, McLaughlin EA, Aitken RJ, Nixon B. Investigation of the expression and functional significance of the novel mouse sperm protein, a disintegrin and metalloprotease with thrombospondin type 1 motifs number 10 (ADAMTS10). Int J Androl. 2012;35(4):572-89.

20. Gibbs GM, Roelants K, O'Bryan MK. The CAP superfamily: cysteine-rich secretory proteins, antigen 5, and pathogenesis-related 1 proteins--roles in reproduction, cancer, and immune defense. Endocr Rev. 2008;29(7):865-97.

21. Gibbs GM, Lo JC, Nixon B, Jamsai D, O'Connor AE, Rijal S, Sanchez-Partida LG, Hearn MT, Bianco DM, O'Bryan MK. Glioma pathogenesis-related 1-like 1 is testis enriched, dynamically modified, and redistributed during male germ cell maturation and has a potential role in sperm-oocyte binding. Endocrinology. 2010;151(5):2331-42.

22. Nixon B, Aitken RJ. The biological significance of detergent-resistant membranes in spermatozoa. J Reprod Immunol. 2009;83(1-2):8-13.

23. Nixon B, Bielanowicz A, McLaughlin EA, Tanphaichitr N, Ensslin MA, Aitken RJ. Composition and significance of detergent resistant membranes in mouse spermatozoa. J Cell Physiol. 2009;218(1):122-34.

24. Caballero J, Frenette G, D'Amours O, Belleannee C, Lacroix-Pepin N, Robert C, Sullivan R. Bovine sperm raft membrane associated glioma pathogenesisrelated 1-like protein 1 (GliPr1L1) is modified during the epididymal transit and is potentially involved in sperm binding to the zona pellucida. J Cell Physiol. 2012;227(12):3876-86.

25. Dun MD, Smith ND, Baker MA, Lin M, Aitken RJ, Nixon B. The chaperonin containing TCP1 complex (CCT/TRiC) is involved in mediating sperm-oocyte interaction. J Biol Chem. 2011;286(42):36875-87.

26. Redgrove KA, Anderson AL, Dun MD, McLaughlin EA, O'Bryan MK, Aitken RJ, Nixon B. Involvement of multimeric protein complexes in mediating the capacitation-dependent binding of human spermatozoa to homologous zonae pellucidae. Dev Biol. 2011;356(2):460-74.

27. Hayasaka S, Terada Y, Inoue N, Okabe M, Yaegashi N, Okamura K. Positive expression of the immunoglobulin superfamily protein IZUMO on human sperm of severely infertile male patients. Fertil Steril. 2007;88(1):214-6.

28. Inoue N, Ikawa M, Okabe M. Putative sperm fusion protein IZUMO and the role of N-glycosylation. Biochem Biophys Res Commun. 2008;377(3):910-4.

29. Earp LJ, Delos SE, Park HE, White JM. The many mechanisms of viral membrane fusion proteins. Curr Top Microbiol Immunol. 2005;285:25-66.

30. Harrison SC. Viral membrane fusion. Nat Struct Mol Biol. 2008;15(7):690-8.

31. Aguilar PS, Baylies MK, Fleissner A, Helming L, Inoue N, Podbilewicz B, Wang $\mathrm{H}$, Wong M. Genetic basis of cell-cell fusion mechanisms. Trends Genet. 2013;29(7):427-37.
32. Hernandez JM, Podbilewicz B. The hallmarks of cell-cell fusion. Development. 2017;144(24):4481-95.

33. Yudin Al, Li MW, Robertson KR, Tollner T, Cherr GN, Overstreet JW. Identification of a novel GPI-anchored CRISP glycoprotein, MAK248, located on the posterior head and equatorial segment of cynomolgus macaque sperm. Mol Reprod Dev. 2002;63(4):488-99.

34. Caballero JN, Frenette G, Belleannee C, Sullivan R. CD9-positive microvesicles mediate the transfer of molecules to bovine spermatozoa during epididymal maturation. PLoS One. 2013;8(6):e65364.

35. Sleight SB, Miranda PV, Plaskett NW, Maier B, Lysiak J, Scrable H, Herr JC, Visconti PE. Isolation and proteomic analysis of mouse sperm detergentresistant membrane fractions: evidence for dissociation of lipid rafts during capacitation. Biol Reprod. 2005;73(4):721-9.

36. Hu J, Merriner DJ, O'Connor AE, Houston BJ, Furic L, Hedger MP, O'Bryan MK. Epididymal cysteine-rich secretory proteins are required for epididymal sperm maturation and optimal sperm function. Mol Hum Reprod. 2018; 24(3):111-22.

37. Lim S, Kierzek M, O'Connor AE, Brenker C, Merriner DJ, Okuda H, Volpert M, Gaikwad A, Bianco D, Potter D, et al. CRISP2 is a regulator of multiple aspects of sperm function and male fertility. Endocrinology. 2019;160(4):915-24.

38. Da Ros VG, Maldera JA, Willis WD, Cohen DJ, Goulding EH, Gelman DM, Rubinstein M, Eddy EM, Cuasnicu PS. Impaired sperm fertilizing ability in mice lacking Cysteine-RIch Secretory Protein 1 (CRISP1). Dev Biol. 2008; 320(1):12-8

39. Maldera JA, Weigel Munoz M, Chirinos M, Busso D, GE Raffo F, Battistone MA, Blaquier JA, Larrea F, Cuasnicu PS. Human fertilization: epididymal hCRISP1 mediates sperm-zona pellucida binding through its interaction with ZP3. Mol Hum Reprod. 2014;20(4):341-9.

40. Cohen DJ, Busso D, Da Ros V, Ellerman DA, Maldera JA, Goldweic N, Cuasnicu PS. Participation of cysteine-rich secretory proteins (CRISP) in mammalian sperm-egg interaction. Int J Dev Biol. 2008;52(5-6):737-42.

41. Maeda T, Nishida J, Nakanishi Y. Expression pattern, subcellular localization and structure--function relationship of rat Tpx-1, a spermatogenic cell adhesion molecule responsible for association with Sertoli cells. Develop Growth Differ. 1999;41(6):715-22.

42. Yamaguchi A, Saito T, Yamada L, Taniguchi H, Harada Y, Sawada H. Identification and localization of the sperm CRISP family protein CiUrabin involved in gamete interaction in the ascidian Ciona intestinalis. Mol Reprod Dev. 2011;78(7):488-97.

43. Urayama S, Harada Y, Nakagawa Y, Ban S, Akasaka M, Kawasaki N, Sawada H. Ascidian sperm glycosylphosphatidylinositol-anchored CRISP-like protein as a binding partner for an allorecognizable sperm receptor on the vitelline coat. J Biol Chem. 2008;283(31):21725-33.

44. Okabe M. Mechanism of fertilization: a modern view. Exp Anim. 2014;63(4): 357-65.

45. Inoue N, Yamaguchi R, Ikawa M, Okabe M. Sperm-egg interaction and gene manipulated animals. Soc Reprod Fertil Suppl. 2007;65:363-71.

46. Ma Z, Zhu P, Shi H, Guo L, Zhang Q, Chen Y, Chen S, Zhang Z, Peng J, Chen J. PTC-bearing mRNA elicits a genetic compensation response via Upf3a and COMPASS components. Nature. 2019;568(7751):259-63.

47. El-Brolosy MA, Kontarakis Z, Rossi A, Kuenne C, Gunther S, Fukuda N, Kikhi K, Boezio GLM, Takacs CM, Lai SL, et al. Genetic compensation triggered by mutant mRNA degradation. Nature. 2019;568(7751):193-7.

48. Dun MD, Mitchell LA, Aitken RJ, Nixon B. Sperm-zona pellucida interaction: molecular mechanisms and the potential for contraceptive intervention. Handb Exp Pharmacol. 2010;198:139-78.

49. Buffone MG, Rodriguez-Miranda E, Storey BT, Gerton GL. Acrosomal exocytosis of mouse sperm progresses in a consistent direction in response to zona pellucida. J Cell Physiol. 2009;220(3):611-20.

50. Bromfield EG, Nixon B. The function of chaperone proteins in the assemblage of protein complexes involved in gamete adhesion and fusion processes. Reproduction. 2013;145(2):R31-42.

51. Reid AT, Lord T, Stanger SJ, Roman SD, McCluskey A, Robinson PJ, Aitken RJ, Nixon B. Dynamin regulates specific membrane fusion events necessary for acrosomal exocytosis in mouse spermatozoa. J Biol Chem. 2012;287(45): 37659-72.

52. Biggers JD, Whitten WK, Whittingham DG. The culture of mouse embryos in vitro. In: Daniel JCJ, editor. Methods in Mammalian Embryology, vol. 86. San Francisco: Freeman Press; 1971. p. 116.

53. Fraser LR. Mouse sperm capacitation in vitro involves loss of a surfaceassociated inhibitory component. J Reprod Fertil. 1984;72(2):373-84. 
54. Nixon B, Maclntyre DA, Mitchell LA, Gibbs GM, O'Bryan M, Aitken RJ. The identification of mouse sperm-surface-associated proteins and characterization of their ability to act as decapacitation factors. Biol Reprod. 2006;74(2):275-87.

55. Nixon B, De luliis GN, Hart HM, Zhou W, Mathe A, Bernstein IR, Anderson AL, Stanger SJ, Skerrett-Byrne DA, Jamaluddin MFB, et al. Proteomic profiling of mouse epididymosomes reveals their contributions to post-testicular sperm maturation. Mol Cell Proteomics. 2019;18(Suppl 1):S91-S108.

56. Zhou W, Sipila P, De luliis GN, Dun MD, Nixon B. Analysis of epididymal protein synthesis and secretion. J Vis Exp. 2018;138.

57. Asquith KL, Baleato RM, McLaughlin EA, Nixon B, Aitken RJ. Tyrosine phosphorylation activates surface chaperones facilitating sperm-zona recognition. J Cell Sci. 2004;117(Pt 16):3645-57.

58. Jeyendran RS, Van der Ven HH, Perez-Pelaez M, Crabo BG, Zaneveld LJ. Development of an assay to assess the functional integrity of the human sperm membrane and its relationship to other semen characteristics. J Reprod Fertil. 1984;70(1):219-28.

59. Nixon B, Bielanowicz A, Anderson AL, Walsh A, Hall T, McCloghry A, Aitken RJ. Elucidation of the signaling pathways that underpin capacitationassociated surface phosphotyrosine expression in mouse spermatozoa. J Cell Physiol. 2010;224(1):71-83.

60. Nixon B, Mitchell LA, Anderson AL, McLaughlin EA, O'Bryan MK, Aitken RJ. Proteomic and functional analysis of human sperm detergent resistant membranes. J Cell Physiol. 2011;226(10):2651-65.

61. Bromfield E, Aitken RJ, Nixon B. Novel characterization of the HSPA2stabilizing protein BAG6 in human spermatozoa. Mol Hum Reprod. 2015; 21(10):755-69.

62. Redgrove KA, Anderson AL, McLaughlin EA, O'Bryan MK, Aitken RJ, Nixon B. Investigation of the mechanisms by which the molecular chaperone HSPA2 regulates the expression of sperm surface receptors involved in human sperm-oocyte recognition. Mol Hum Reprod. 2013;19(3):120-35.

63. Redgrove KA, Nixon B, Baker MA, Hetherington L, Baker G, Liu DY, Aitken RJ. The molecular chaperone HSPA2 plays a key role in regulating the expression of sperm surface receptors that mediate sperm-egg recognition. PLoS One. 2012;7(11):e50851.

64. Towbin H, Staehelin T, Gordon J. Electrophoretic transfer of proteins from polyacrylamide gels to nitrocellulose sheets: procedure and some applications. Proc Natl Acad Sci U S A. 1979;76(9):4350-4.

65. Zhou W, De luliis GN, Turner AP, Reid AT, Anderson AL, McCluskey A, McLaughlin EA, Nixon B. Developmental expression of the dynamin family of mechanoenzymes in the mouse epididymis. Biol Reprod. 2017;96(1):159-73.

66. Borg CL, Wolski KM, Gibbs GM, O'Bryan MK. Phenotyping male infertility in the mouse: how to get the most out of a 'non-performer'. Hum Reprod Update. 2010;16(2):205-24.

67. Gibbs GM, Orta G, Reddy T, Koppers AJ, Martinez-Lopez P, de la Vega-Beltran JL, Lo JC, Veldhuis N, Jamsai D, McIntyre P, et al. Cysteine-rich secretory protein 4 is an inhibitor of transient receptor potential M8 with a role in establishing sperm function. Proc Natl Acad Sci U S A. 2011;108(17):7034-9.

68. Bromfield EG, Aitken RJ, Anderson AL, McLaughlin EA, Nixon B. The impact of oxidative stress on chaperone-mediated human sperm-egg interaction. Hum Reprod. 2015;30(11):2597-613.

\section{Publisher's Note}

Springer Nature remains neutral with regard to jurisdictional claims in published maps and institutional affiliations.

Ready to submit your research? Choose BMC and benefit from:
- fast, convenient online submission
- thorough peer review by experienced researchers in your field
- rapid publication on acceptance
- support for research data, including large and complex data types
- gold Open Access which fosters wider collaboration and increased citations
- maximum visibility for your research: over 100M website views per year
At BMC, research is always in progress.
Learn more biomedcentral.com/submissions

